\title{
Dialects, Cultural Identity, and Economic Exchange
}

Oliver Falck

Stephan Heblich

Alfred Lameli

Jens Südekum

Stirling Economics Discussion Paper 2011-01

January 2011

Online at

http://www.management.stir.ac.uk/research/economics/workingpapers 


\title{
Dialects, Cultural Identity, and Economic Exchange
}

\author{
Oliver Falck $^{+}$, Stephan Heblich ${ }^{*}$, Alfred Lameli ${ }^{\ddagger}$, Jens Südekum $^{\dagger}$
}

January 2011

+ Ifo Institute for Economic Research, CESifo and Max Planck Institute of Economics. Address: Poschingerstr. 5, D-81679 Munich (Germany), Phone: +49 899224 1370, Email: falck@ifo.de

* University of Stirling, IZA and SERC. Address: Division of Economics, Stirling, FK9 4LA (UK), Phone: +44 178646 7481, Email: stephan.heblich@stir.ac.uk.

* Research Centre Deutscher Sprachatlas, Address: Hermann-Jacobsohn-Weg 3, D-35032 Marburg (Germany), Phone: +49 64212822 482, Email: lameli@ staff.uni-marburg.de.

${ }^{\dagger}$ Mercator School of Management, University of Duisburg-Essen, IZA, CESifo and Ruhr Graduate School of Economics. Address: Lotharstraße 65, D-47057 Duisburg (Germany), Phone: +49 203379 2357, Email: jens.suedekum@uni-due.de

Acknowledgments: We thank Sascha Becker, Kristian Behrens, Davide Cantoni, Brad DeLong, Klaus Desmet, Gilles Duranton, Edward Glaeser, Claudia Goldin, Michael Greenwood, Avner Greif, Jeffrey Grogger, Hubert Jayet, Nicola Fuchs-Schündeln, William Kerr, Walter Krämer, Mario Larch, Björn Lüders, Yasusada Murata, Jost Nickel, Henry Overman, Marcello Pagnini, Marco Percoco, Klaus Schmidt, Matthew Turner, and seminar participants in Chicago, Stanford, Berkeley, Barcelona, Amsterdam, IZA Bonn, Frankfurt, Nürnberg, Hannover, Marburg and Stirling for insightful comments and suggestions. We also thank conference participants at the American Economic Association Annual Meeting 2011 in Denver, the World Congress of the Econometric Society 2010 in Shanghai, the European Economic Association Annual Meeting 2010 in Glasgow, the Annual Meeting of the Urban Economics Association 2010 in Denver, the Annual Meeting of the Society for Applied Linguistics 2010 in Leipzig, and the Meeting of Bavarian and Austrian Dialectologists 2010 in Passau. Parts of this paper were written while Falck was visiting Harvard University and Heblich was visiting the University of Toronto. They acknowledge the hospitality of these institutions. The usual disclaimer applies. 


\title{
Dialects, Cultural Identity, and Economic Exchange
}

\begin{abstract}
We study the effect of cultural ties on economic exchange using a novel measure for cultural identity: dialect similarity across regions of the same country. We evaluate linguistic microdata from a unique language survey conducted between 1879 and 1888 in about 45,000 German schools. The recorded geography of dialects comprehensively portrays local cultural ties that have been evolving for centuries, and provides an ideal opportunity to measure cultural barriers to economic exchange. In a gravity analysis, we then show that cross-regional migration flows in the period 2000-2006 are positively affected by historical dialect similarity. Using different empirical strategies, we show that this finding indicates highly timepersistent cultural borders that impede economic exchange even at a fine geographical scale.
\end{abstract}

JEL Codes: $\quad$ R23; Z10; J61

Keywords: Dialects; Language; Culture; Internal migration; Gravity; Germany 
"It is impossible for an Englishman to open his mouth without making some other Englishman hate or despise him" (George Bernhard Shaw — Pygmalion, 1916)

\section{Introduction}

Scholars from various disciplines have long argued that economic phenomena are affected by culture, but quantitative research on the impact of cultural ties on economic exchange has started only very recently. Culture is not an easily operational concept, however, and is thus difficult to measure. Specifically, proxies for cultural ties are often available only at a high level of aggregation, typically for different countries, and may thus coincide with other effects on economic outcomes, such as institutions. We develop a novel approach for studying the economic implications of cultural ties. Our units of analysis are small-scale regions of the same country (Germany) across which institutional barriers are much lower than between countries. We explore - for the first time in the economics literature - linguistic micro-data, which provide a unique opportunity to comprehensively measure deep and persistent cultural ties at an unusual degree of detail: the region-pair level. ${ }^{1}$

Our data are derived from an encompassing language survey conducted by the linguist Georg Wenker between 1879 and 1888. This survey was intended to provide an in-depth inquiry into language variation within the newly created German Empire, at a time where a standardized national language ("Hochdeutsch") had not yet become prevalent, and where people even from neighboring villages were often not able to properly communicate with each other. It includes detailed grammatical and phonological attributes (such as the pronunciation of consonants and vowels) of the German spoken by pupils in about 45,000 schools

\footnotetext{
1 There is an extensive literature about language and economics which has mostly discussed language acquisition by foreigners or the coexistence of domestic and foreign languages within one country, see e.g. Lazear (1999), Rauch (1999), Rauch and Trindade (2002), Alesina and La Ferrara (2005), Melitz (2008), or Ginsburgh and Weber (2010). Our focus is different in that we study regional variation of the same language. The only other economic study we are aware of that exploits linguistic variation within the same language is Grogger (2011). He finds that black workers in the United States systematically earn lower wages if their speech can be distinctively identified as African-American English. Our focus is different in that we are not interested in labor market discrimination against particular dialects (or sociolects), but in the effects of cultural similarity (represented by dialect similarity) on economic exchange.
} 
from all over the Empire. ${ }^{2}$ Below we provide several examples of our data showing that the geography of dialects as recorded in the late $19^{\text {th }}$ century is the outcome of an evolutionary process and — almost like a genome - stores information about historical interactions across the German regions that would be very difficult, if not impossible, to capture without linguistic data. That language data are extremely useful in that regard is not a new idea; in fact, already Charles Darwin advocated the use of linguistic data when he wrote, in his seminal book, Origin of Species:

If we possessed a perfect pedigree of mankind, a genealogical arrangement of the races of man would afford the best classification of the languages now spoken around the world; and if all extinct languages, and all intermediate and slowly changing dialect, were to be included, such an arrangement would be the only possible one. (cited after Cavalli-Sforza 2000:167).

We then investigate to what extent this historical dialect similarity affects contemporaneous economic exchange across German regions. It is well established among linguists that dialect use is less common today than in the $19^{\text {th }}$ century. Dialects hardly represent actual communication barriers anymore, since standard German is now widespread. They are thus unlikely to affect economic decisions through a transaction cost mechanism as in Lazear (1999), where individuals have to speak a common language to economically interact with each other. Nevertheless, dialects still affect contemporaneous economic decisions because they reflect those persistent cultural similarities across German regions.

More specifically, we study the impact of culture on gross migration flows across 439 German districts (NUTS 3 regions). We develop a location choice model with random utility in the spirit of Anderson et al. (1992), where individual migration decisions are governed by idiosyncratic and region-specific factors as well as by region-pair-specific mobility costs.

\footnotetext{
2 To this day, the Wenker survey is the most complete documentation ever of a nation's language and has defined standards in the linguistics discipline (for a detailed introduction, see Lameli 2008). Similar data are not available for other countries or languages at a comparable degree of regional detail.
} 
From the model we derive a testable gravity equation for regional gross migration flows that we then take to the data. Such migration flows are a well suited economic outcome variable for our purpose, because migration (also across regions) typically occurs only rarely in an individual's lifetime. Cultural factors are thus likely to influence such decisions even more strongly than, say, they would the decision to trade goods or to conduct financial transactions with someone from a different region.

The gravity equation features source and destination area fixed effects which capture regionspecific economic variables such as wages, unemployment, housing prices, etc., but also unobservable attributes, such as amenities, institutions, or historical factors that vary only at the regional level. Pecuniary mobility costs are captured by the physical distances and the travel times across regions, following the seminal approaches by Schwartz (1973) and Greenwood (1975). Yet, research on internal migration has consistently shown that migration decisions are also accompanied by significant costs other than and in addition to the strictly economic ones. In a classic article, Sjaastad (1962) has coined the term "psychic costs of migration", which include the costs of leaving "familiar surroundings" and therefore encapsulate cultural differences across regions that affect location decisions. The region-pair-specific dialect similarity allows us, as one of the first attempts in the literature, to directly proxy these "psychic mobility costs" and to quantify their effect on migration flows.

Our central finding is that contemporaneous migration is significantly positively affected by the similarity of the dialects prevalent in the source and the destination area more than 120 years ago. The impact is economically important: Had there been no dialect barriers, internal migration in Germany would be almost 20 per cent higher than it actually is.

We argue that this finding can be interpreted as the impact of culture on regional migration decisions. In other words, our results indicate that migration is impeded by intangible and highly time-persistent cultural borders which limit the degree of integration of the national 
labor market. This interpretation rests on three important conditions: 1) that the historical dialects are a relevant measure for contemporaneous cultural ties, 2) that the impact of dialect similarity is not confounded with other factors that drive contemporaneous migration and that are also correlated with the recorded historical dialect patterns, and 3) that there is no persistence of migration flows due to some omitted factors, so that these persistent migration flows have inter alia shaped the geography of dialects.

To address the first issue, we explore linguistic data from a recent language survey. Even if absolute language patterns across regions have become more similar over time, we still find that the relative linguistic similarities that Georg Wenker has recorded in the $19^{\text {th }}$ century have remained highly stable. A simple OLS regression of migration on current dialect similarity reveals a significantly positive coefficient. Since current dialect similarity is likely to be endogenous to the contemporaneous level of migration, one would expect this coefficient to be upward biased. Yet, when using the historical dialects as an instrument in a two-stage specification, it turns out that the IV coefficient is significantly larger than the OLS coefficient. This suggests that dialects matter for migration decisions not because people would be literally unable to communicate in other regions, but that historical dialect differences represent a persistent underlying factor — cultural differences — across German regions.

We then take into account the two other possible sources of endogeneity. We address omitted variable bias and show that dialect similarity is not confounded with other types of region-pair-specific congruencies, like a common religious or political history, a similar industry structure, or connectedness through ancient trading routes. Consistent with the argument by Charles Darwin, our study indeed suggest that linguistic data capture an entirety of historical imprints and otherwise immeasurable aspects of cultural identity. We then address the possibility of a spurious correlation that could result from a persistence of migration flows. 
Exploiting the quasi-natural experiment of German Reunification, we analyze if network effects may have led to persistence in migration flows and, in turn, to dialect assimilation. Furthermore, by focusing on subsamples of regions with similar geological features, we address the possibility that migration flows are driven by persistent omitted factors over the very long run.

Our study is related to a recent line of research on the economic effects of cultural differences at the international level. Guiso et al. (2009) show that trade and investment flows across countries are impeded by intangible borders that stem from a lack of bilateral trust. This bilateral lack of trust is explained, inter alia, by cultural differences across countries, which are in turn measured by differences in religious, genetic, and somatic traits. Our study adds to this literature by showing that cultural borders to economic exchange also exist within nations and, hence, on a much finer geographical scale. ${ }^{3}$ Furthermore, our study allows us to abstract from distortions such as institutional barriers, which are difficult to separate from the effect of culture in a cross-country analysis, as those other distortions surely matter more at the international than at the regional level.

Tabellini (2010) studies the interaction of culture and institutions in determining output differences across European regions. Recognizing that contemporaneous cultural values are endogenous to current economic outcomes, he instruments culture with historical regional variables on literacy rates and political institutions. In our study, we directly observe past cultural similarity across regions by relying on dialects measured in the $19^{\text {th }}$ century and, therefore, face no comparable simultaneity problem.

The remainder of this paper is organized as follows. In Section 2 we describe our linguistic data and discuss the meaning of dialects, especially in the historical context of our study.

\footnotetext{
${ }^{3}$ Cultural and genetic differences are also put in perspective by Desmet et al. (2008), who show that countries with more distant gene profiles exhibit stronger differences in cultural values. Spolaore and Wacziarg (2009) find a positive relationship of genetic and current income differences across countries. These papers thus emphasize that genetic similarity stimulates economic exchange via a cultural channel. We obtain a consistent result for linguistic similarity on a much finer spatial scale.
} 
Section 3 sets out a simple gravity model for regional gross migration flows that serves as the underlying framework for the empirical analysis. Section 4 presents our baseline results, and Sections 5 and 6 are devoted to various extended analyses that shed light on the economic interpretation of our results. Section 7 concludes.

\section{Background and data}

\subsection{Historical background and the measurement of linguistic characteristics}

In the centuries following Charlemagne, France, Spain, England, and Habsburg Austria developed into states where power was wielded by a centralized sovereign. In contrast, the Holy Roman Empire became increasingly fragmented. When the Treaty of Westphalia ended the Holy Roman Empire in 1648, what we know as Germany today was comprised of hundreds of sovereign kingdoms, principalities, and dukedoms. This fragmentation continued until the German Empire (Deutsches Reich) was established in the late $19^{\text {th }}$ century.

Georg Wenker conducted his language survey shortly after the Empire was established. Between 1879 and 1888, he asked teachers and pupils in more than 45,000 schools to translate 40 German sentences into their local dialect. These sentences were especially designed to reveal specific dialect characteristics. The survey covered the entire area of the Empire and revealed pronounced differentiation of local languages, since at that time (more so than today) dialects were the people's common everyday speech.

Wenker's surviving material contains millions of phonological and grammatical observations in the form of handwritten protocols of the language characteristics recorded in the individual schools (see Figure 1a for an example). These raw data were integrated by Wenker and collaborators into a linguistic atlas of the German Empire (Sprachatlas des Deutschen Reichs). The Sprachatlas was developed between 1889 and 1923 and contains more than 1,600 hand-drawn maps showing the detailed geographical distribution of particular lan- 
guage characteristics across the German Empire (see Figure 1b for an example). In an evaluation process that spanned several decades, Ferdinand Wrede, Wenker's successor in the linguistic atlas project, determined 66 prototypical characteristics that are most relevant for the structuring of the German language area. ${ }^{4}$ Each of those characteristics has to do with the pronunciation of consonants and vowels as well as with grammar. An individual map exists for each of those 66 linguistic attributes. ${ }^{5}$

\section{[FIGURES 1a AND 1b HERE]}

We matched these 66 thematic maps with Germany's current administrative classification scheme. The Federal Republic of Germany currently consists of 439 districts (Landkreise); however, the linguistic maps from the Sprachatlas do not conform to this classification system. We therefore use GIS (Geographical Information System) technology to juxtapose digitized versions of these linguistic maps and the map of the current administrative districts. We then quantify the dialect of each district in the form of binary variables.

The following example illustrates this approach. One of the linguistic attributes is the German word for pound. Depending on the dialect, it is pronounced as "Pfund," "Pund," or "Fund." The corresponding map in the Sprachatlas shows the variant "Fund" mostly in the eastern parts of Germany, "Pund" mostly in the northern areas, and "Pfund" mostly in the southern parts. These variants are then transferred into a binary coding of the type: "Fund" $=\left\{\begin{array}{lll}1 & 0 & 0\end{array}\right\} ; "$ "Pund" $=\left\{\begin{array}{lll}0 & 1 & 0\end{array}\right\} ; "$ "Pfund" $=\left\{\begin{array}{llll}0 & 0 & 1\end{array}\right\}$. Comparing the individual linguistic map for the word pound and the current administrative map of Germany, we assign one of these codes to each of the 439 districts. This approach is unambiguous when there is no intra-regional variation of this particular language characteristic, i.e., when the entire area of some district $r$ exhibited the same pronunciation according to the map in the Sprachatlas.

\footnotetext{
${ }^{4}$ Wrede combined local extractions of variants to a dialect classification (see Wrede et al. 1927-1956, map 56). One advantage of this classification over more recent categorizations of the Wenker data (e.g., Wiesinger 1983 b) is that it lends itself quite easily to a mathematical representation of dialects (see below).

5 All hand-drawn maps are published online as the 'Digitaler Wenker-Atlas' (DiWA), see http://www.diwa.info.
} 
Typically this has been the case. However, the spatial distribution of this particular language attribute and the current boundaries of the districts are not in all cases perfectly coincident. If we found intra-regional variation of pronunciation, we then chose the most frequent variant within the district as representative. The entire matching procedure was accompanied by several linguistic plausibility tests and cross-checks with the underlying raw data on the phonetic protocols from the Wenker survey.

Repeating this procedure for all 66 language characteristics, which can have between 2 and 18 realizations, we end up with $\mathrm{K}=383$ binary variables representing the dialect that was spoken in the area of a district in the late $19^{\text {th }}$ century. More formally, the historical dialect of the current district $r$ is represented by a vector $\mathbf{i}^{r}=\left\{i_{1}^{r}, i_{2}^{r}, \cdots, i_{K}^{r}\right\}$ of length $\mathrm{K}=383$, where each vector element is a binary variable $[0,1]$. Using these data, we can then construct a dialect similarity matrix across all $R=439$ regions as follows: consider any two German regions $r$ and $s$ whose historical dialects are represented by $\mathbf{i}^{r}=\left\{i_{1}^{r}, i_{2}^{r}, \cdots, i_{K}^{r}\right\}$ and $\mathbf{i}^{s}=\left\{i_{1}^{s}, i_{2}^{s}, \cdots, i_{K}^{s}\right\}$, respectively. To quantify the overlap of these two vectors, we use a simple count similarity measure, namely $\ell_{r s}=\mathbf{i}^{r} \times \mathbf{i}^{s}$, where $0 \leq \ell_{r s} \leq 66$ for $r \neq s$ and $\ell_{r r}=66$. The resulting matrix across all regions then has dimension $439 \times 439$ with generic elements $\ell_{r s}$. As a robustness check we also consider the similarity index by Jaccard (1901) which is computed as follows: Given the two vectors $\mathbf{i}^{r}$ and $\mathbf{i}^{s}$, let $M_{11}$ be the number of vector columns where both $\mathbf{i}^{r}$ and $\mathbf{i}^{s}$ have the value $1, M_{10}$ the number of cases where $\mathbf{i}^{r}$ has a 1 and $\mathbf{i}^{s}$ has a $0, M_{01}$ the number of cases where $\mathbf{i}^{r}$ has a 0 and $\mathbf{i}^{s}$ has a 1 , and $M_{00}$ the number of cases where both vectors have a 0 . The Jaccard index is then defined as $M_{11} /\left(M_{11}+M_{10}+M_{01}\right)$. It ranges between zero and one, with a higher value indicating a higher degree of dialect similarity. Table 1 provides some summary statistics. For our pre- 
ferred count similarity measure, the average number of linguistic correspondences across all regional pairs is $\bar{\ell}_{r s}=32.6$ with a standard deviation equal to 10.53 .

\section{[Table 1 HERE]}

\subsection{What does dialect similarity capture?}

Nations are not monolithic linguistically. Typically, there are hundreds of regional dialects within the same language. Such phonological and grammatical variations across space are by no means random, but they have developed over centuries in a process of linguistic evolution and, therefore, reflect various imprints from the past. The quote from the introduction suggests that Charles Darwin was already aware of this point, and a vast subsequent literature has further dwelled on the fact that both genes and languages are correlated and the product of evolution. ${ }^{6}$ As such, both exhibit an enormous degree of persistence. Yet, anthropologists such as Cavalli-Sforza (2000) argue that language differences across groups tend to be better visible than genetic ones, as they develop relatively more quickly and show more variation. In this subsection we discuss some examples of our German data. These examples suggest that the geography of dialect similarity as recorded in the $19^{\text {th }}$ century, in fact, reflects longterm evolutionary processes of region-pair-specific congruencies and past interactions.

Our first example illustrates the interrelations between dialects and religious similarities. The map on the left in Figure 2 depicts the regional similarities to the dialect spoken in Waldshut, a district located in the southwest of Germany (Baden-Württemberg). The reference point Waldshut is marked. Warm colors indicate a high, and cold colors a low degree of similarity. The map on the right in Figure 2 zooms in on Baden-Württemberg and compares the spatial pattern of dialect similarity with the religious geography of that area. As is well known, the

\footnotetext{
${ }^{6}$ Linguistic studies on this relationship include Barbujani et al. (1996), Dupanloup de Ceuninck et al. (2000), and Manni (2010). For a broader discussion, also see the "linguistic dynamics approach" developed by Schmidt (2010).
} 
Reformation of the $16^{\text {th }}$ century resulted in distinct Protestant and Catholic localities in Germany (see also Becker and Woessmann 2009). Protestant areas in the year 1546 are indicated in Figure 2 by a hatching from left to right, whereas the hatching from right to left indicates those areas that were Catholic in 1546 but became Protestant by 1820 . Notice that there are only very few such areas, i.e., religious orientation remained remarkably stable over this time span of almost 300 years. This stability is chiefly due to social practice. For example, in earlier times it was uncommon, if not completely unheard of, to marry across religious borders; Protestants marry Protestants, Catholics marry Catholics. ${ }^{7}$

\section{[FIGURE 2 HERE]}

The main message conveyed by Figure 2, however, is that the geography of dialect similarity is strikingly similar to religious geography. Waldshut itself was and always remained Catholic, and it can be seen that the dialects of other Catholic districts resemble the one in Waldshut more closely than do the dialects of Protestant districts. This finding aligns itself nicely with an evolutionary perspective on linguistic development. Catholic localities have been in closer contact with other Catholic localities; Protestants have been more in contact with other Protestants. Hence, religious and linguistic similarities have co-evolved, and recent linguistic studies suggest that they do so until today (see Stoeckle 2010).

Second, language is also reflective of previous migration waves. To illustrate this point, let us consider the example of the Goslar district. The map in Figure 3 illustrates the dialect similarity between Goslar (white) and all other German districts.

\section{[FIGURE 3 HERE]}

Linguists view the Harz Mountains in Goslar as a language enclave in the sense that the dialect spoken there is not similar to dialects spoken in neighboring districts but instead more

\footnotetext{
${ }^{7}$ This stability is remarkable in light of the fact that it was not until after the Peace of Westphalia (1648) that a newly-converted ruler became prohibited from forcing his new religion on his subjects, which had been common practice ever since the Peace of Augsburg in 1555 (see Cantoni 2009). Other factors apart from social practice that might have a stabilizing effect on religious orientation include natural boundaries such as the Black Forest or the Rhine, or administrative borders, in this case the border of the archbishopric Freiburg.
} 
resembles a dialect spoken about 300 kilometers away in the mountainous Erzgebirge, where, in Figure 3, we find an accumulation of warm colors (indicating high similarity). The historical explanation for this phenomenon is the revival of silver mining in the Goslar area between 1520 and 1620, motivating migration to that area by starving miners in Saxony. This $16^{\text {th }}$-century relationship between the two regions is still visible in dialect data from the late $19^{\text {th }}$ century, which illustrates the degree of inertia inherent to evolutionary processes.

Third, geographical distance certainly plays a role in dialect similarity. As seen in Figure 2, the districts adjacent to Waldshut tended to have similar dialects. However, we also find districts relatively close to Waldshut that are less similar than districts that are farther away. This suggests that our dialect data contain information that goes beyond what can be explained by mere physical distance, a point made clearly by the Goslar example (Figure 3), where there is virtually no relationship between geographical distance and dialect similarity. Dialect similarity could, however, still reflect the existence of old trading routes, which, by taking advantage of rivers, natural passages, and forts, historically led to more contact between certain regions. And, indeed, the importance of transport routes for the spatial structuring of language attributes is made evident by the example of the so-called Rheinstaffel. Klausmann (1990) notes a difference in linguistic development depending on the topological relation of individual locations to the Rhine river, i.e., dialect similarity may also be influenced by ancient transportation networks.

Last, at the time Wenker collected the data, the German Empire had just been created out of formerly independent territories. These territories had previously been in existence for centuries, and thereby also contributed to linguistic evolution. In fact, dialectologists since the $19^{\text {th }}$ century were aware of the congruencies between the areal distribution of historical territories and language (see Haag 1898; Aubin et al. 1926; and, more recently, Barbour and Stevenson 1990). One reason for this persistence may be that the territories tended to encourage internal 
traffic, and discourage, or at least not improve the means for, travel external to their borders. Hence, communication and exchange between territories was somewhat hindered (Bach 1950:81). From an evolutionary perspective, such limitations can lead to a higher degree of dialect similarities among regions that formerly belonged to the same historic territory.

Summing up, these examples suggest that dialect similarity between regions is higher the more intensive was their interaction and exchange in the course of history. Those influences, such as common religious and historical political borders, distance and the influences of ancient transportation networks, as well as unique historical events and previous migration waves, all left some long-lasting imprints on the local dialects. Dialect similarities between regions are thus correlated with these types of regional congruencies, but are likely to capture many further (and less well measurable) aspects of cultural similarity.

\section{A gravity model of current regional migration}

In the empirical analysis we investigate to what extent cultural differences affect current cross-regional migration flows. In this section, we derive a theoretically grounded gravity equation for migration, which serves as the underlying framework.

\subsection{Current regional migration data}

We use data on pair-wise gross migration flows for the 439 German districts averaged over the period 2000-2006 as provided by the German Federal Statistical Office. ${ }^{8}$

\section{[TABLE 2 HERE]}

Table 2 provides an overview of these data and points out two basic facts about internal migration flows in Germany. First, it indicates that the average annual gross flow between a pair of regions was only seven migrants per 100,000 inhabitants in the district of origin,

\footnotetext{
${ }^{8}$ In Germany, every person who changes his or her place of residence is legally required to register at the new residence within at most two weeks (even earlier in some states). The migration data are thus very accurate.
} 
which implies a total gross emigration rate of roughly $3 \%$ for the typical German district. Gross migration flows in Germany are thus relatively small compared to countries like the US, which suggests that mobility costs are substantial. Second, across all regional pairs, there has been some gross migration in more than $96 \%$ of all cases. That is, migration occurs not only from economically poor to rich regions, but also in the other direction. Our gravity model for migration accommodates those features. It takes into account that individuals are heterogeneous and face distance-dependent mobility costs should they decide to move, and it generates two-way gross migration flows which are larger than net flows.

\subsection{The model}

We consider a simple discrete location choice model with random utility (see Anderson et al. 1992). Assume a country that consists of $r=1, \ldots, R$ regions, and a mass of heterogeneous individuals indexed by $h$. Indirect utility of individual $h$ in region $r$ is given by

$$
V_{r}^{h}=u_{r}+\varepsilon_{r}^{h}
$$

The term $u_{r}$ is region-specific and identical across individuals. It includes economic variables like labor and housing market conditions, as well as all regional features that affect everyone in that region in the same way. The term $\varepsilon_{r}^{h}$ is idiosyncratic for $h$ and $r$, capturing heterogeneity in the way how region-specific features affect different individuals. For example, this term may include job signals from different regions or occupational shocks pertaining to that particular person $h$, as well as his or her view on local amenities.

We refer to the term $u_{r}$ as the average welfare of region $r$, and for our purposes it suffices to think of $u_{r}$ as being exogenously given. That is, we assume that the average welfare levels do not respond to the individual location decisions. ${ }^{9}$ For the idiosyncratic term $\varepsilon_{r}^{h}$ we assume

\footnotetext{
${ }^{9}$ See Murata (2003) and Tabuchi and Thisse (2002) for economic geography frameworks that incorporate a random utility model. Those papers consider welfare to be endogenous and solve for long-run equilibria.
} 
that the actual matching value between an individual and a region is the realization of a random variable. Specifically, we assume that $\varepsilon_{r}^{h}$ is distributed i.i.d. across individuals and regions, and we adopt the standard parameterization of a double exponential distribution, $F(x)=\operatorname{Pr}\left(\varepsilon_{r}^{h} \leq x\right)=\exp [-\exp (-x / \beta-\gamma)]$, where $\gamma(\approx 0.5572)$ is the Euler constant, and $\beta>0$ is a parameter. This distribution has mean zero and variance $\left(\pi^{2} / 6\right) \cdot \beta^{2} \approx 1.6449 \cdot \beta^{2}$. The term $\beta$ is referred to as the degree of heterogeneity of the idiosyncratic shocks. If cross-regional mobility was costless, the choice probability of some individual $h$ to live in region $r$ would be given as follows (see Murata 2003):

$$
P_{r}=\operatorname{Pr}\left[V_{r}^{h}>\max _{j \neq r}\left\{V_{j}^{h}\right\}\right]=\frac{\exp \left[u_{r} / \beta\right]}{\sum_{j=1}^{R} \exp \left[u_{j} / \beta\right]}
$$

With $\beta \rightarrow 0$, people make deterministic location choices based only on the average welfare levels. On the other hand, with $\beta \rightarrow \infty$, idiosyncratic shocks become extremely heterogeneous and people choose among the $R$ regions with equal probability $(1 / R)$.

We now embed this model into a two-period framework and introduce region-pair-specific mobility costs. Suppose there is some innate distribution of individuals across regions. The random variables $\varepsilon_{r}^{h}$ are drawn at the end of the first period. Given the realizations of the $\varepsilon_{r}^{h}$ and the values of $u_{r}$, individuals then choose the location they most prefer during the second period. An individual $h$ migrates from the initial location $r$ to some other region $s$ if the overall utility from living in $s$, net of the mobility costs $c_{r s}$, exceeds the (net of mobility costs) utility level of all other locations $j$, including the location of birth $r$. Formally, a move from $r$ to $s$ takes place if $V_{s}^{h}-c_{r s}>\max _{j \neq s}\left\{V_{j}^{h}-c_{r j}\right\}$, with $c_{r r}=0$ and $c_{r j} \geq 0$ if $j \neq r$. Using (2), the probability of migrating from $r$ to $s$ is then $P_{r s}=\exp \left[\left(u_{s}-c_{r s}\right) / \beta\right] / \sum_{j=1}^{R} \exp \left[\left(u_{j}-c_{r j}\right) / \beta\right]$. Aggregating across individuals, the gross migration flow from $r$ to $s$ is equal to 
$M_{r s}=P_{r s} \cdot L_{r}$, where $L_{r}$ is the population size of the source region. Rearranging $P_{r s}=M_{r s} / L_{r}$ and taking logs we obtain the following gravity equation: $\log \left(M_{r s} / L_{r}\right)=\left(u_{s}-c_{r s}\right) / \beta-\log \left[\sum_{j=1}^{R} \exp \left[\left(u_{j}-c_{r j}\right) / \beta\right]\right]$

Notice that the location choice in our framework may involve the decision of an individual to migrate to an area with a lower level of average welfare than in the current source region, as well as the decision to remain in the region of birth. Furthermore, due to the idiosyncratic shocks, the model features parallel gross migration flows from $r$ to $s$ and from $s$ to $r$.

Turning to the specification of the mobility costs, we not only include standard pecuniary costs (for moving furniture, finding accommodation, etc.), which are denoted by $d_{r s}$. We also incorporate, in the spirit of Sjaastad (1962), non-pecuniary costs of migration denoted by $\ell_{r s}$, which capture the psychic costs of moving to a culturally unfamiliar environment. We assume the following specification: $c_{r s}=a_{1} \cdot \log \left[d_{r s}\right]+a_{2} \cdot \log \left[\ell_{r s}\right]$, so that we can rewrite the gravity equation and arrive at our final equation to be estimated:

$$
\log \left(M_{r s} / L_{r}\right)=D_{r}+D_{s}+\alpha_{1} \cdot \log \left[d_{r s}\right]+\alpha_{2} \cdot \log \left[\ell_{r s}\right]+e_{r s}
$$

where $e_{r s}$ is a standard error term. Notice that the term $D_{r}=-\log \left[\sum_{j=1}^{R} \exp \left(\left(u_{j}-c_{r j}\right) / \beta\right)\right]$ varies only at the level of the source region, whereas the term $D_{s}=u_{s} / \beta$ varies only at the level of the destination region. These terms are therefore captured by source and destination area fixed effects in the empirical analysis. The mobility costs vary at the region-pair level. In the empirical analysis, we measure pecuniary mobility costs $d_{r s}$ by the physical distances and travel time across German regions (see Table 1 above for some summary statistics thereof), and the cultural mobility costs $\ell_{r s}$ inversely by the dialect similarities across regions. 
A specification like Equation (3) is standard practice in the gravity literature in international trade. The fixed effects capture all region-specific impact variables in our cross-sectional analysis, such as contemporaneous wages, prices and amenities, as well as institutions and further historically determined regional characteristics. The fixed effects also tackle the problem of interdependent flows in a multi-region economy (Anderson and van Wincoop 2003), since the term $D_{r}$ captures the overall position of the source area within the entire network of regions (its "multilateral resistance term"). As shown by Feenstra (2004), this specification allows for a consistent estimation of region-pair-specific impacts. The coefficients of interest are the geographical distance elasticity $\alpha_{1}$ and, in particular, the elasticity $\alpha_{2}$, which measures the impact of cultural similarity on gross migration flows. ${ }^{10}$

\section{The effect of dialect similarity on regional migration}

\subsection{Baseline results}

We estimate the gravity equation (Equation (3)) by ordinary least squares with origin and destination fixed effects. Table 3 presents the baseline estimation results. ${ }^{11}$

\section{[TABLE 3 HERE]}

The results show that dialect similarity has a positive and highly statistically significant effect on gross regional migration flows. When including only dialect similarity without controlling for geographical distance, as in specification 1, we find a sizable positive impact on internal migration in Germany. The (scaled) elasticity of gross migration with respect to dialect similarity is around 2.2.

As illustrated by the examples in Section 2, dialect similarity is correlated with geographical distance, which per se has a negative impact on migration flows. To address this issue we

\footnotetext{
${ }^{10}$ Since we have $\alpha_{2}=a_{2} / \beta$, we can identify this elasticity up to the unobservable constant $1 / \beta$.

${ }^{11}$ All estimation results reported in this paper refer to the total stock of migrants and regional populations irrespective of age. Results are similar, however, when considering only working-age individuals.
} 
first separately study the impact of geographical distance without considering dialect similarity. In specification 2 we use the linear physical distance between the centers of the source and the destination district as our proxy for pecuniary mobility costs. The results show that increasing the physical distance between two regions, all else equal, drives down gross migration flows. The elasticity in absolute terms is about 1.5. In specification 3 we use an alternative distance measure, namely, the travel time by car between any pair of regions (in minutes). This proxy may better capture the true regional accessibilities, as it takes into account irregularities in distances due to natural barriers like rivers or mountains. The results indicate that the elasticity with respect to travel time (1.77) is a bit larger than for physical distance. When including both measures at the same time (as in specification 4), it turns out that most of the negative impact is captured by physical distances, with travel time having some additional small impact. Altogether, these findings are consistent with the previous migration literature that has established a detrimental effect of geographical distance on migration flows (see, e.g., Schwartz 1973; Greenwood 1975).

The important question is whether the positive effect of dialect similarity on migration flows prevails once we control for geographical distance. In specification 5 we simultaneously include dialect similarity and both proxies of pecuniary mobility costs. ${ }^{12}$ As can be seen, the coefficient $\alpha_{2}$ drops substantially compared to column 1, which is due to the correlation of linguistic and geographical distance. However, even conditional on geographical distance (and origin and destination fixed effects), we find a positive and highly significant effect of dialect similarity on gross migration flows. The estimated elasticity is 0.186 . We take this elasticity (column 5 of Table 3) as our baseline finding throughout this paper.

\footnotetext{
${ }^{12}$ In the literature on how genetic similarities affect international trade flows, Giuliano et al. (2006) argue that there may actually be no such effects once transport costs across countries are properly controlled for. Our estimation in column 5 takes such issues into account because actual travel time across regions can be thought of as an analogue of actual transport costs for goods.
} 
To set this result into perspective, recall from Table 1 that the standard deviation of our dialect similarity measure is 10.53 , which is about 32 percent of the sample mean. Thus, an increase of dialect similarity by one standard deviation (measured at the sample mean) increases gross migration flows between a pair of regions by about 6 percent. We can also separate the direct effect of distance on migration, and the indirect effect operating through dialects. A simple OLS regression across all regional pairs reveals that increasing physical distance by $100 \mathrm{~km}$ reduces dialect similarity by 4.23 linguistic correspondences on average, i.e., by around $40 \%$ of a standard deviation. We can then calculate that decreasing geographical distance by $100 \mathrm{~km}$ raises gross migration flows by roughly $41 \%$ directly, and by another 2-3\% because dialects have been more similar. Finally, we can calculate the overall impact of dialect barriers on regional migration in Germany. If, hypothetically, all dialects had been identical ( $\ell_{r s}=66$ for all $r, s$ ), this would be tantamount to an increase of dialect similarity by $102.35 \%$ at the sample mean. Given the estimated baseline elasticity, this implies an increase of regional gross migration flows by about $19 \%$, so that the average gross emigration rate of the typical German district would rise from $3.11 \%$ to about $3.71 \%$.

Columns 6 and 7 of Table 3 address the robustness of our main finding with respect to the estimation method. First, the interpretation of the parameters of log-linear gravity models estimated by linear least squares methods can be misleading in the presence of heteroskedasticity. To overcome this problem, we estimate the gravity equation by means of a Poisson pseudo-maximum-likelihood (PPML) estimator with Eicker-White robust standard errors, as proposed by Santos-Silva and Tenreyro (2006). Second, previous work in the international trade literature suggests that zero flows can pose problems in the estimation of gravity equations (see Disdier and Head 2008; Helpman et al. 2008). As shown above, zero gross migration flows across German districts account for less than $4 \%$ of all cases and therefore would appear to be a minor issue. Nevertheless, we tackle this potential problem by employing a 
two-stage Heckman procedure that uses a non-linear probit equation for selection into migration in the first stage, and then estimates Equation (3) in the second stage. ${ }^{13}$ In the PPML estimation (see column 6), the elasticity with respect to dialect similarity is around 0.11 and thus somewhat lower than in the baseline specification. The Heckman selection model (column 7) yields estimates that are similar to the baseline finding.

Finally, in column 8 we replace the simple count index with the similarity index by Jaccard (1901) while returning to ordinary least squares estimation. As can be seen, our results are similar to the baseline specification which suggests that our results are also robust with respect to the linguistic similarity index.

\subsection{Effect heterogeneity and further robustness checks}

In Table 4 we investigate the effect of dialect similarity on migration flows for different types of region pairs. In particular, we divide the 439 German districts into 178 urban and 261 peripheral regions using the common classification system of the Federal Office for Building and Regional Planning, and then distinguish four categories of flows: urban-tourban (U-U), peripheral-to-peripheral (P-P), urban-to-peripheral (U-P), and peripheral-tourban $(\mathrm{P}-\mathrm{U})$. These four different samples thus permit us to investigate whether the impact of dialect similarity on migration decisions is dependent on whether the source and the destination area are rather heterogeneous (as in the U-P and the P-U case) or homogeneous (as in the U-U and the P-P case). The results in Table 4 show that the estimated elasticity is similar in all cases, suggesting that our baseline result is not driven by particular types of regional migration flows. ${ }^{14}$

\section{[TABLE 4 HERE]}

\footnotetext{
${ }^{13}$ We thus rely on the normality assumption for identification of our second-stage estimates.

${ }^{14}$ The elasticity is lower for the P-P sample, but it should be noted that zero migration flows are concentrated within this group. Although the P-P sample accounts for only $35 \%$ of all region pairs, it includes $56.6 \%$ of all zero flows. When using the Heckman-estimator for the P-P sample, which specifically deals with the zero flow problem, we obtain a coefficient $0.096^{* * *}$ (std.error 0.015) which is again closer to the baseline finding.
} 
To further study effect heterogeneity, we have again used the full sample of region pairs and dropped all flows where the destination region is a major city with more than 500,000 inhabitants. Those migrations may be mainly motivated by the career concerns of young workers, who temporarily move because human capital investments are easier in big cities (Glaeser 1999; Peri 2002), whereas cultural affinity may play a lesser role in those cases. Furthermore, to tackle a possible non-linearity in the impact of distance on migration, we have dropped all flows below some minimum distance $(50,100$, or $150 \mathrm{~km})$, as individuals may not have to leave their cultural environment over those short distances. We omit the detailed results, but the effect of dialect similarity on migration hardly changes in those additional robustness checks. Results also do not change qualitatively when we control for geographical distance, travel time and dialect similarity in levels instead of logs, and also include squared terms of those variables. This confirms that a possible non-linearity in the impact of distance on migration does not crucially affect our results. Finally, we have augmented the baseline specification with a dummy variable that equals unity if the source and the destination region are not located within the same federal same state (Bundesland). Crossing the border of a federal state may systematically increase pecuniary mobility costs, e.g., because of different regulations and laws applicable to various occupational groups (e.g., for teachers and lawyers). It turns out that state borders reduce gross migration flows. The effect of dialect similarity on migration hardly changes, however.

\subsection{Discussion of the baseline result}

The results reported so far imply that an individual who decides to migrate today, all else equal, prefers destinations with a dialect similar to the one prevalent in his or her source region more than 120 years ago. Our interpretation of this finding is that dialect differences 
capture intangible cultural barriers at the region-pair level, which significantly impede migration in Germany. This interpretation rests on three important conditions:

1. That the historical dialect differences from the $19^{\text {th }}$ century are indeed a relevant measure for contemporaneous cultural differences across German regions.

2. That the impact of dialect similarity is not confounded with other factors that drive contemporary migration and that are correlated with the recorded historical dialect patterns. If that were the case, dialect similarity would just be a proxy for "something else" and our estimations would suffer from an omitted variable bias.

3. That the causality is indeed such that dialect (cultural) differences affect migration. The alternative hypothesis would be that migration flows are persistent over time due to some omitted factors, and that they have inter alia shaped the geography of dialects. If that were the case, our estimations would capture a spurious correlation.

In the next sections we subsequently address these concerns, thereby shedding light on the economic interpretation of our baseline result.

\section{Language and culture}

\subsection{Instrumental variable approach}

Are historical language patterns only a proxy for contemporaneous dialect differences? Or do the historical dialects reveal underlying persistent cultural differences across German regions? To address these questions we explore recent regional language data in this section. Analyzing the current dialect situation in Germany is difficult, since there is no recent comprehensive language inquiry comparable to the Wenker survey, at least not for the country as a whole. What is available, however, is a comprehensive dialect survey for 69 Bavarian districts referring to the time period from the 1980s till today. These data come from the Bava- 
rian linguistic atlas project (Bayerischer Sprachatlas, "BSA") and allow us to recover today's spatial distribution of the same language characteristics as in the original Wenker survey, and to build a contemporaneous dialect similarity matrix across 69 Bavarian regions in an analogous way as described above. ${ }^{15}$

Figure 4 gives an example. The map on the left illustrates dialect similarity to the district of Passau using the contemporaneous BSA data. The map on the right uses the data from the $19^{\text {th }}$ century and depicts dialect similarity with Passau for the same group of regions.

\section{[FIGURE 4 HERE]}

The two maps look virtually identical, which suggests that the geography of dialects remained remarkably stable over time. This conclusion also holds more generally. The correlation between the historical and the contemporaneous dialect similarity matrix is 0.85 , which suggests that relative linguistic differences are highly persistent. ${ }^{16}$ Furthermore, comparing the historical and the contemporaneous dialect vectors $\mathbf{i}^{r}$ for every region, respectively, we find that $81.68 \%$ of all entries are identical and less than $18 \%$ of the evaluated language characteristics differ between the historical data and the recent data. That is, even in absolute terms there seems to be no substantial change in the language patterns in Bavaria during this time period of 120 years. ${ }^{17}$

This high degree of persistence is probably overstated by the BSA data, because it is not a representative language survey of the residence populations but focuses on elderly male per-

\footnotetext{
${ }^{15}$ The BSA data are available from http://www.baydat.uni-wuerzburg.de. At the time of our data collection the data from the northern part of Bavaria were not available yet. These Bavarian data are especially well suited for our purpose since many larger dialect regions (Bavarian, Swabian, East-Franconian, Rhine-Franconian, Thuringian) meet in Bavaria, making it one of the most dynamic German language regions.

${ }^{16}$ This correlation even increases to 0.88 if one corrects the BSA-matrix for changes in linguistic evaluation techniques since the Wenker survey, and for the few missing values where single language characteristics are not reported for single Bavarian districts.

${ }^{17}$ There are a few additional linguistic case studies on dialect change in Germany, which are mostly dedicated to specific language phenomena. Those studies also note a close correspondence of the current geography of dialects with historical linguistic patterns (e.g., Bellmann 1985:213). In the economic literature, the transmission of cultural values across generations and the stability of cultural patterns over time is further studied in Tabellini (2008) and Benabou and Tirole (2006).
} 
sons without prior migration experiences. In a representative cross-section of the population it could be the case that language patterns have converged more across regions on average, since the number of dialect speakers is lower. In fact, it is well established among linguists that dialect use is less common today than in the $19^{\text {th }}$ century, and that dialects today hardly represent actual communication barriers anymore. In the $19^{\text {th }}$ century, a standardized national language ("Hochdeutsch") had not yet been developed, and people from different regions of the country were not able to properly communicate with each other. Such conversations are far easier today, as the standardized language is much more widespread. The ubiquity of modern mass media is one factor that has facilitated this diffusion; the migration that has occurred during the $20^{\text {th }}$ century is another factor that contributed to the local languages. However, even if absolute language differences across regions have gone down over time, they have certainly not been nullified completely. Furthermore, with smaller absolute differences there can still be strong persistence of relative linguistic differences across regions. And these relative differences can still represent persistent cultural differences across German regions, which affect contemporaneous migration decisions even if dialects no longer pose actual communication barriers for the individuals.

To study these issues, we now turn to an instrumental variable (IV) approach. Column 1 of Table 5 first reports the results of a standard fixed effects OLS regression of contemporaneous dialect similarity on regional gross migration flows across the 69 Bavarian regions. Column 2 reports the results of an IV specification where we use historical dialect similarity as an instrument for contemporaneous dialect similarity. The F-value of the excluded instrument $(6,291.7)$ indicates that this instrument is indeed highly relevant. Overall, the IV specification supports our main conclusion that dialect similarity positively affects regional migration flows. Comparing the magnitudes of the coefficients, we find that the estimated elasticity is almost twice as large in the IV than in the OLS specification. 


\section{[TABLE 5]}

This downward bias of the OLS estimator suggests that dialect differences in fact represent cultural differences across regions. If the impact of dialects on migration would just be about communication barriers, we would expect an upward bias in the OLS regression since language patterns today are more similar between districts with high contemporaneous migration flows. Table 5 suggests, however, that there is some measurement error in the contemporaneous dialect data, probably due to the diffusion described above, that downward biases our estimate. By contrast, the historical dialects are a cleaner measure of persistent cultural ties than the contemporaneous language data are. The IV approach thus leads to a reduction of the attenuation bias resulting from this measurement error, and hence to a larger estimated elasticity than in the OLS regression. ${ }^{18}$

\subsection{Omitted region-pair-specific variables}

If the geography of dialects is persistent over time, the question still remains if cultural differences are properly captured by linguistic differences. In that regard, the question remains if there are other persistent (cultural or non-cultural) factors that drive contemporary migration and that are also correlated with historical dialect patterns. In this subsection we deal with this issue of omitted variable bias. Notice that our benchmark estimations are consistent as long as omitted variables are purely region-specific, due to the fixed effects specification of our empirical model. A problem would arise, however, if we omit relevant region-pairspecific variables that simultaneously affect dialects and migration patterns.

Culture is, of course, not restricted to language, but occurs in many other domains such as art, traditions, habits, etc. Yet, a vast literature in anthropology and sociology insists that cultural and linguistic evolution proceed in parallel, and that language is the strongest marker

\footnotetext{
${ }^{18}$ Using the first stage coefficient of historical on contemporaneous dialect similarity (see column 2 of Table 5), we can convert our baseline elasticity (column 5 in Table 3) into an elasticity of current migration with respect to contemporaneous dialect similarity. This would be $0.276(=0.186 / 0.674)$, but this calculation has to be taken cautiously as it assumes that the first stage coefficient derived from the Bavarian sample can be generalized to Germany as a whole.
} 
of cultural identity (see, e.g., Cavalli-Sforza 2000; Brewer 1991). That is, if two regions share many traditions and habits, this indicates that those regions had numerous interactions in the course of history. This, however, would have left lasting imprints on language structures as well, i.e., similarities within those other cultural domains should be reflected in dialect differences. This implies that linguistic similarity is a relevant and comprehensive measure of deep cultural ties at the regional level.

It is still important to analyze if really dialects impact on migration flows, or rather something else that is correlated with dialects. Specifically, we argued in Section 2 that dialect similarity reveals a spatial pattern that often corresponds to other types of historically determined congruencies between the regions, including religious orientation as indicated by the Waldshut example (Figure 2). We therefore control for differences in religious denominations in 1890 , roughly the same time at which the linguistic data were collected. We define a dummy variable that equals unity if the majority of the population in the source region had a different religion than those in the destination region in the late $19^{\text {th }}$ century. If cultural differences between current German regions are manifested mainly along those religious lines, and if dialects simply pick up these persistent effects of religion, we would expect the elasticity of migration with respect to dialect similarity to turn insignificant (or at least to drop substantially) once we include this additional control variable.

Second, the Goslar example (Figure 3) has emphasized the role of industry structures in driving migration flows. If two regions are persistently specialized in the same sectors, there may be constantly more migration between them as human capital is at least partly industryspecific. This industry similarity may continue to drive migration to the extent that local sectoral structures do not change over time. To take this into account, we have constructed an index of historical differences in industrial structures across regional pairs. Data for 24 industries are available for the year 1907, and are taken from the German workplace and popu- 
lation census. Industrial differences are then calculated as the sum of absolute differences in employment shares over the 24 industries across the different pairs of regions.

Third, another possible confounding factor are former administrative borders, since we emphasized above that the geography of dialect similarity is also correlated with the borders between the territories out of which the German Empire was created (as noted, e.g., by Barbour and Stevenson 1990). We therefore include a dummy that equals unity if the current migration flow extends across a historical administrative border. ${ }^{19}$

Finally, even though we control for contemporaneous travel distances across regions, dialect similarity may also pick up persistent effects of ancient trading routes and transportation networks that have formerly linked particular pairs of regions and, thus, facilitated exchange between them. To cope with this issue, we have calculated a measure for historical travel distance based on a comprehensive German railway system outline by Friedrich List in 1833 (see the data appendix for further details).

\section{[TABLE 6 HERE]}

In columns 1 to 4 of Table 6 we control for the new variables separately; they are considered jointly in column 5 . The results suggest that there is significantly more migration between regions with historically different religious denominations, and less migration between regions with stronger differences in their historical industrial structures. The presence of a historical administrative border exerts a negative impact on current migration flows. Historical travel distance does not turn out to be significant when it is considered jointly with contemporaneous travel distance. ${ }^{20}$

\footnotetext{
${ }^{19}$ More specifically, we consider the borders of 38 member states and 4 independent cities that were part of the German Confederation at the time of its foundation in 1815. These borders are not only a good representation for the administrative boundaries that prevailed until the German Empire was established, but also for tariff borders because the German Confederation was not successful in establishing a free trade area within the confederation.

${ }^{20}$ The positive effect of religious differences on migration may seem counterintuitive. However, it may capture an enduring prosperity difference between Catholic and Protestant areas, which was recognized early on by
} 
The main insight of Table 6 , however, is that the elasticity of migration with respect to dialect similarity hardly changes when including those new control variables. This suggests that our results do not suffer from omitted variable bias, since dialects do not merely reflect religious, sectoral or political congruencies across regions. These results are consistent with the view that language structures are a comprehensive indicator of cultural similarity that measures an entirety of historical imprints and domains of culture.

\section{Persistence of migration flows}

Turning now to the third estimation issue discussed in Section 4, there is still the concern that migration, rather than culture, is persistent over time and has, inter alia, shaped the geography of dialects. Dialect similarity would then not actually cause contemporary migration, and our estimations would capture a spurious correlation.

\subsection{The German re-unification as a quasi-natural experiment}

Such persistence in migration can be due to network effects, which result in a clustering of migrants from particular source regions at particular destinations. To illustrate this, suppose that at the time Georg Wenker collected the linguistic data, there was already a previously established migration connection between two regions $r$ and $s$. Say, families have constantly migrated across those two regions, because the regions traditionally offered suitable jobs due to similar industrial structures, or because of existing networks of social contacts. ${ }^{21}$ To the extent that these network effects remain in operation, they constantly influence migration decisions, which in turn would lead to a correlation of region-pair-specific migration flows

\footnotetext{
Max Weber and studied further by Becker and Woessmann (2009). Moreover, we find that the historical border dummy turns insignificant when we add current administrative borders in the same way as described in Section 4. This suggests that current and historical borders overlap, so that the historical borders partly capture the negative impact of federal state borders on migration that operates via an increase in pecuniary mobility costs. Finally, instead of historical differences we could also control for contemporaneous differences in industrial structures. Our main result for the impact of dialect similarity would not change.

${ }^{21}$ Network effects in migration are extensively studied both theoretically (Carrington et al. 1996) and empirically (e.g., Munshi 2003).
} 
over time. If this is so, the prediction could be that dialect distance slowly disappears between those regions $r$ and $s$ experiencing high migration exchange.

To address this issue, we exploit a quasi-natural experiment in German history. Since the construction of the Berlin Wall in 1961, migration flows between East and West Germany were exogenously cut off. ${ }^{22}$ In other words, persistent migration flows that might have caused ongoing dialect assimilation between particular East and West German regions, as well as other types of cross-border contacts, were almost completely interrupted for a considerable time span between the Wenker survey and our current migration data.

When migration between the East and the West became again possible after 1989, the preexisting migration networks have thus not been in operation for almost 30 years. To the extent that these networks have no "memory", we would thus not expect to see a continuation of the persistence in migration flows across particular pairs of regions that existed prior to the division of Germany. ${ }^{23}$ On the other hand, dialect similarity does have such a memory, as emphasized by our various examples, and is likely to have survived the division.

Put differently, if our baseline findings only reflect the persistence of migration flows, we would expect to find no (or at least substantially lower) effects of dialect similarity within a sample of migration flows across the inner German border only. By contrast, if we still find a positive effect of dialect similarity on contemporary migration flows for these cases, such would suggest that cultural similarity actually does affect migration decisions.

[TABLE 7 HERE]

\footnotetext{
${ }^{22}$ The division and reunification of Germany is used as a quasi-natural experiment by Redding and Sturm (2008), who show that the decline of West German cities near the inner German border can be attributed to the loss of market access to the neighboring East German areas after the division of Germany.

${ }^{23}$ Networks based on similar industry structures were likely to be seriously damaged, because the central planning in the East German economy has led to major perturbations in the spatial distribution of industries (see, e.g., Heinzmann and Karrasch, 1990). The survival of social networks was put under strain by the severe restrictions on personal interactions and face-to-face communications across the inner German border. According to literature on social networks, such personal interactions are essential for the prevalence of a network, which in the absence of communication exhibits a rapid depreciation (see, e.g., Glaeser et al. 2002).
} 
Table 7 shows the results for the East-West and the West-East samples of region pairs and, indeed, the coefficient of language similarity is still significantly positive and of similar magnitude as in the benchmark specification. These results are thus much more in line with an effect of persistent cultural similarity on migration flows, rather than with the opposite causality of persistence in migration flows.

\subsection{First-nature geographical features}

Finally, in the last step of the analysis, we investigate another possible source of persistence in migration flows. Specifically, there may be deep regional differences that have persistently driven migration flows over the course of history and, thereby, also linguistic development. In particular, think of first-nature geographical features which have determined the economic prosperity of the regions over the very long run. Salient candidates are indicators of a region's suitability for agriculture and forestry, all of which were major sources of wealth before the Industrial Revolution.

As argued by Combes et al. (2010), soil characteristics can be regarded as a major determinant of local labor demand in an agrarian society. Accordingly, geological indicators for the suitability of the soil for agriculture and forestry should provide a meaningful insight into the distribution of regional wealth before the heyday of industrialization. These soil characteristics should then be related to ancient migration patterns. As regions with good soil tended to be economically prosperous, they were likely to attract mass migration waves, particularly from areas with bad soil characteristics. A similar point can be made for the slope of a region, which is also likely to have influenced agricultural productivity, hence regional prosperity, in former times. Slope may have had another effect on ancient migration patterns transport routes probably avoided large differences in steepness or ruggedness. 
If these very basic geological factors have affected migration waves over the very long run, they could also have influenced the spatial pattern of dialects in Germany. Specifically, the smaller the difference in soil quality and the larger the slope difference between two regions, the lower the probability that local populations interacted very often. This, in turn, may have resulted in less similar dialects between such regions. To the extent that these geological features still affect current regional migration, our estimations may be capturing a spurious correlation between dialect similarity and migration flows.

To address this possible source of endogeneity, we again create different subsamples of regions that limit the degree of heterogeneity of the respective source and destination areas. In particular, we classify regions with "good" and with "bad" soil quality. Good soil is suitable and imposes no limitations for agriculture, whereas bad soil imposes such limits because the soil is overly gravelly, stony, or lithic. ${ }^{24}$ Using this classification scheme, we can create subsamples of regional pairs and separately study migration flows for cases where both the source and the destination area have good soil, where the source has bad but the destination has good soil, etc. A similar approach is adopted to distinguish between regions with different slope characteristics. Slope is measured as the difference between the maximum and minimum elevation in meters within a region. We can then classify "steep" (above average) and "flat" (below average) regions and create appropriate samples of regional pairs.

For pairs of regions with similar soil and slope characteristics, we may expect very long-run push and pull effects to matter relatively little. This may have led to few cross-regional contacts and therefore to little dialect assimilation over the very long run. In other words, if we find that dialect similarity matters for current migration also for these homogeneous pairs of regions, then a long-run persistence of migration flows is unlikely to be reason. Such a find-

\footnotetext{
${ }^{24}$ We are indebted to Gilles Duranton for providing the data for these indicators (see the Appendix and Combes et al. for a more detailed description). To use current indicators of soil quality we need to assume that soil characteristics have not changed during the past centuries, and there are good reasons to believe that this condition is met by our binary distinction between good and bad soil. We also tried a variety of other indicators related to the climate and soil of a region, but this did not crucially affect our empirical results.
} 
ing would rather suggest that there is actually a genuine effect of cultural similarity on migration decisions. The results of our gravity estimation for these samples of regional pairs are reported in Table $8 \mathrm{a}$ and $8 \mathrm{~b}$, respectively.

\section{[TABLES 8a AND 8b HERE]}

As can be seen, the results are qualitatively similar for all the considered samples. That is, even for those cases where source and destination area are relatively homogeneous in their geographical features, we find a positive and significant impact of dialect (cultural) similarity on current gross migration flows (see columns 1 and 2 of Tables $8 \mathrm{a}$ and $8 \mathrm{~b}$ ).

Results do not change when we additionally control for the similarity of the industry structure in the source and destination area and the historical connectedness of regions via ancient trading routes (see Section 5.2), which is a sensible exercise since first-nature geographical features may also have influenced industry compositions and transport networks and thereby have an indirect effect on current migration flows. Results also do not change qualitatively when considering an encompassing specification where all control variables and all dummy variables used for sample splits that we have considered so far are included all at once. ${ }^{25}$

\section{Conclusion}

In this paper, we have evaluated detailed linguistic micro-data from the $19^{\text {th }}$ century on the intra-national variation of phonological and grammatical attributes within the German language. In our empirical analysis we find an economically meaningful effect of historical dialect similarity on current regional migration flows. This finding implies that there are intangible cultural borders within a country that impede economic exchange across its regions. These intangible regional borders in Germany are enormously persistent over time; they have been developed over centuries, and so they are likely to be there also tomorrow.

\footnotetext{
${ }^{25}$ Specifically, when using the same specification as in column 5 of Table 6 , and including additional dummy variables for region pairs along the dimensions urban/periphery, East/West Germany, good/bad soil and flat/steep slope, we obtain an elasticity of migration with respect to historical dialect similarity equal to $0.084 * * *$ (std.error 0.026). This is lower than the baseline estimate, but still highly statistically significant.
} 
Even on a low geographical level people seem to be unwilling to move to culturally unfamiliar environments. The average Bavarian will not easily move to Saxony, nor vice versa, unless he or she is compensated by considerably better economic prospects or job opportunities in the other region. The existence of cultural borders thus clearly limits mobility across local labor markets and, thus, the integration of the national labor market.

It is beyond the scope of this paper to discuss whether it is possible, or desirable, to downsize such borders. Policy initiatives in the European Union aiming for a preservation of regional languages tend to suggest that there is currently no interest in cultural equalization, but rather that linguistic diversity is perceived as valuable for a society. It is thus a natural extension for future research to explore the welfare consequences of cultural differences at a low geographical level in greater detail.

\section{References}

Alesina, A., and E. La Ferrara (2005). Ethnic Diversity and Economic Performance. Journal of Economic Literature, 43(3), 762-800.

Anderson, J. E., and E. van Wincoop (2003). Gravity with Gravitas: A Solution to the Border Puzzle. American Economic Review 93(1), 170-192.

Anderson, S. P., A. de Palma, and J.-F. Thisse (1992). Discrete Choice Theory of Product Differentiation. Cambridge, MA: MIT Press.

Aubin, H., T. Frings, and J. Müller (1926). Kulturströmungen und Kulturprovinzen in den Rheinlanden. Geschichte, Sprache, Volkskunde. Bonn: Röhrscheid.

Bach, A. (1950). Deutsche Mundartforschung. Ihre Wege, Ergebnisse und Aufgaben. $2^{\text {nd }}$ edition. Heidelberg: Winter.

Barbujani, G., M. Stenico, L. Excoffier, and L. Nigro (1996). Mitochondrial DNA Sequence Variation Across Linguistic and Geographic Boundaries in Italy. Human Biology 68(2), 201-215.

Barbour, S., and P. Stevenson (1990). Variation in German. A Critical Approach to German Sociolinguistics. Cambridge: Cambridge Univ. Press.

Becker, S. O., and L. Woessmann (2009). Was Weber Wrong? A Human Capital Theory of Protestant Economic History. Quarterly Journal of Economics 124(2), 531-596.

Bellmann, G. (1985). Substandard als Regionalsprache. In G.Stötzel (ed.) GermanistikForschungsstand und Perspektiven. Part 1: Germanistische Sprachwissenschaft. Berlin, New York: de Gruyter, 211-218.

Benabou, R., and J. Tirole (2006). Belief in a Just World and Redistributive Politics. Quarterly Journal of Economics 121, 699-746. 
Brewer, M. B. (1991). The Social Self: On Being the Same and Different at the Same Time. Personal and Social Psychology Bulletin 17(5), 475-482.

Cantoni, D. (2009). The Economic Effects of the Protestant Reformation: Testing the Weber Hypothesis in the German Lands. Harvard Univ. Working Paper.

Carrington, W.J., E. Detragiache, and T. Vishwanath (1996). Migration with Endogenous Moving Costs. American Economic Review 86(4), 909-930.

Cavalli-Sforza, L. L. (2000). Genes, Peoples, and Languages. London: Penguin.

Chambers, J. K., and P.Trudgill (1998). Dialectology. $2^{\text {nd }}$ edition. Cambridge: Cambridge Univ. Press.

Combes, P.-P., G. Duranton, L. Gobillon, and S. Roux (2010). Estimating Agglomeration Economies with History, Geology, and Worker Effects. In E. Glaeser (ed.) The Economics of Agglomeration, Chicago: Univ. of Chicago Press.

Crystal, D. (1987). The Cambridge Encyclopedia of Language. Cambridge: Cambridge Univ. Press.

Desmet, K., M. Le Breton, I. Ortuno-Ortin, and S. Weber (2009). The Stability and Breakup of Nations: A Quantitative Analysis. Unpublished Manuscript, Universidad Carlos III Madrid.

Disdier, A.-C., and K. Head (2008). The Puzzling Persistence of the Distance Effect on Bilateral Trade. Review of Economics and Statistics 90(1), 37-48.

Dupanloup de Ceuninck, I., S. Schneider, A. Langaney, and L. Excoffier (2000). Inferring the Impact of Linguistic Boundaries on Population Differentiation: Application to the Afro-Asiatic-Indo-European Case. European Journal of Human Genetics 8(10), 750756.

Feenstra, R. (2004). Advanced International Trade. Princeton: Princeton Univ. Press.

Ginsburgh, V. and S. Weber (2010). The Economics of Linguistic Diversity - How Many Languages Make Sense?. Forthcoming: Princeton: Princeton Univ. Press.

Giuliano, R., A. Spilimbergo, and G. Tonon (2006). Genetic, Cultural and Geographical Distances. IZA Working Paper 2229.

Glaeser, E. L. (1999). Learning in cities. Journal of Urban Economics 46(2), 254-277.

Glaeser, E. L., D. Laibson, and B. Sacerdote (2002). An Economic Approach to Social Capital. Economic Journal 112(483), 437-458.

Greenwood, M. J. (1975). Research on Internal Migration in the United States: A Survey. Journal of Economic Literature 13(2), 397-433.

Grogger, J. (2011). Speech Patterns and Racial Wage Inequality. Forthcoming: Journal of Human Resources

Guiso, L., P. Sapienza, and L. Zingales (2009). Cultural Biases in Economic Exchange? Quarterly Journal of Economics 124(3), 1095-1131.

Haag, K. (1898). Die Mundarten des oberen Neckar- und Donaulandes. Reutlingen: Hutzler.

Heinzmann, J. and P. Karrasch (1990). Spatial Patterns of Technological Change in the G.D.R. Geoforum 21(2), 193-201.

Helpman, E., M. Melitz, and Y. Rubinstein (2008). Estimating Trade Flows: Trading Partners and Trading Volumes. Quarterly Journal of Economics 123(2), 441-487. 
Hunt, J. (2006). Staunching Emigration from East Germany: Age and the Determinants of Migration. Journal of the European Economic Association 4, 1014-1037.

Jaccard, P. (1901). Étude comparative de la distribution florale dans une portion des Alpes et des Jura. Bulletin del la Société Vaudoise des Sciences Naturelles 37, 547-579.

Klausmann, H. (1990). Staatsgrenze als Sprachgrenze? Zur Entstehung einer neuen Wortund Sprachgebrauchsgrenze am Oberrhein. In: Kremer, L and H. Niebaum (eds.) Grenzdialekte. Studien zur Entwicklung kontinentalwestgermanischer Dialektkontinua. Hildesheim, Zürich, New York: Olms, 193-210.

Lameli, A. (2008). Was Wenker noch zu sagen hatte...Die unbekannten Teile des 'Sprachatlas des deutschen Reichs'. Zeitschrift für Dialektologie und Linguistik 75(3), 255-281.

Lazear, E. P. (1999). Culture and Language. Journal of Political Economy 107(6), S95S126.

Manni, F. (2010). Sprachraum and Genetics. In: A. Lameli, R. Kehrein, and S. Rabanus (eds.) Language and Space. Vol. 2: Language Mapping. Berlin, New York: de Gruyter, 524-541.

Melitz, J. (2008). Language and Foreign Trade. European Economic Review 52(4), 667-699.

Munshi, K. (2003). Networks in the Modern Economy: Mexican Migrants in the U.S. Labor Market. Quarterly Journal of Economics 118(2), 549-600.

Murata, Y. (2003). Product Diversity, Taste Heterogeneity, and Geographic Distribution of Economic Activities: Market vs. Non-Market Interactions. Journal of Urban Economics 53(1), 126-144.

Peri, G., (2002). Young Workers, Learning and Agglomerations. Journal of Urban Economics 52(3), $582-607$.

Rauch, J. (1999). Networks Versus Markets in International Trade. Journal of International Economics 48(1), 7-35.

Rauch, J., and V. Trindade (2002). Ethnic Chinese Networks in International Trade. Review of Economics and Statistics 84(1), 116-130.

Redding, S. J., and D. M. Sturm (2008). The Costs of Remoteness: Evidence from German Division and Reunification. American Economic Review 98(5), 1766-97.

Santos Silva, J. M. C., and S. Tenreyro (2006). The Log of Gravity. Review of Economics and Statistics 88(4), 641-658.

Schmidt, J.E. (2010). Linguistic Dynamics Approach. In: Auer, P. and J.E.Schmidt (eds.) Language and Space. An International Handbook. Vol. 1: Theories and Methods. Berlin, New York: Mouton de Gruyter, 201-225.

Schwartz, A. (1973). Interpreting the Effect of Distance on Migration. Journal of Political Economy 81(5), 1153-1169.

Sjaastad, L. A. (1962). The Costs and Returns of Human Migration. Journal of Political Economy 70(5), 80-93.

Spolaore, E., and R. Wacziarg (2009). The Diffusion of Development. Quarterly Journal of Economics 124(2), 469-529.

Steger, H., E. Gabriel, and V. Schupp (1989). Südwestdeutscher Sprachatlas. Marburg: Elwert. 
Stoeckle, P. (2010): Subjektive Dialektgrenzen im alemannischen Dreilandereck, In: Hundt, M., C.A. Anders, and A. Lasch (eds.) perceptual dialectology-Neue Wege der Dialektologie. Berlin, New York: de Gruyter, 291-315.

Tabellini, G. (2008). The Scope of Cooperation: Norms and Incentives. Quarterly Journal of Economics 123(3), 905-950.

Tabellini, G. (2010). Culture and Institutions: Economic Development in the Regions of Europe. Journal of the European Economic Association 8(4), 677-716.

Tabuchi,T., and J.-F. Thisse (2002). Taste Heterogeneity, Labor Mobility and Economic Geography. Journal of Development Economics 69(1), 155-177.

Wiesinger, P. (1983a). Deutsche Dialektgebiete außerhalb des deutschen Sprachgebiets: Mittel-, Südost- und Osteuropa, in: W. Besch et al. (eds.) Dialektologie. Ein Handbuch zur deutschen und allgemeinen Dialektforschung. Zweiter Halbbd. Berlin, New York: de Gruyter, 900-930.

Wiesinger, P. (1983b). Die Einteilung der deutschen Dialekte. In: W. Besch et al. (eds.) Dialektologie. Ein Handbuch zur deutschen und allgemeinen Dialektforschung. Zweiter Halbbd. Berlin, New York: de Gruyter, 807-900.

Wrede, F., W. Mitzka, and B. Martin (1927-1956). Deutscher Sprachatlas. Auf Grund des von Georg Wenker begründeten Sprachatlas des Deutschen Reichs. Marburg: Elwert. 
Table 1: Descriptive Statistics of the Similarity and Distance Measures

\begin{tabular}{|c|c|c|c|c|c|}
\hline & Obs. & Mean & Std. Dev. & Min & Max \\
\hline $\begin{array}{l}\text { Dialect } \\
\text { Similarity }\end{array}$ & 96,141 & 32.60 & 10.53 & 11 & 66 \\
\hline $\begin{array}{l}\text { Dialect Similarity } \\
\text { (Jaccard) }\end{array}$ & 96,141 & 0.344 & 0.156 & 0.091 & 1 \\
\hline Geographical Distance (in kilometers) & 96,141 & 309.69 & 152.33 & 1.07 & 845.32 \\
\hline Travel Distance (in minutes) & 96,141 & 263.33 & 113.44 & 8.80 & 683.31 \\
\hline
\end{tabular}

Notes: Descriptive Statistics are provided for 96,141 pairs of regions $r$ and $s(r \neq s$ and $r=s=439)$. See section 2.1. for the definition of the linguistic similarity indices.

Table 2: Descriptive Statistics of Gross Migration Flows, Average 2000-2006

\begin{tabular}{lcc}
\hline \hline & $\begin{array}{c}\text { Mean of } \\
M_{r s} / L_{r}\end{array}$ & $\begin{array}{c}\text { Mean of all positive } \\
M_{r s} / L_{r} \\
\text { (per 100,000 inhabitants) }\end{array}$ \\
German inhabitants, entire population & (per 100,000 inhabitants) & 7.35 \\
$\begin{array}{l}\text { German inhabitants, working-age population } \\
(18-65)\end{array}$ & 7.11 & $96.75 \%$ \\
\hline
\end{tabular}

Notes: Means are calculated across 192,282 observations for migration flows from every region $r$ to $s(r \neq s$ and $r=s=439)$. The number of positive observations is 186,025 (184,667) for the entire population (working-age population). 
Table 3: Baseline Results_-FE-OLS Regressions

\begin{tabular}{|c|c|c|c|c|c|c|c|c|}
\hline & $\begin{array}{c}(1) \\
\ln \left(M_{r S} / L_{r}\right) \\
\text { OLS }\end{array}$ & $\begin{array}{c}(2) \\
\ln \left(M_{r s} / L_{r}\right) \\
\text { OLS }\end{array}$ & $\begin{array}{c}(3) \\
\ln \left(M_{r s} / L_{r}\right) \\
\text { OLS }\end{array}$ & $\begin{array}{c}(4) \\
\ln \left(M_{r s} / L_{r}\right) \\
\text { OLS }\end{array}$ & $\begin{array}{c}\ln \left(M_{r s}^{(5)} / L_{r}\right) \\
\text { OLS }\end{array}$ & $\begin{array}{c}(6) \\
M_{r s} \\
\text { Poisson }\end{array}$ & $\begin{array}{c}(7) \\
\ln \left(M_{r s} / L_{r}\right) \\
\text { Heckman }\end{array}$ & $\begin{array}{c}\ln \left(M_{r s} / L_{r}\right) \\
\text { OLS }\end{array}$ \\
\hline $\begin{array}{l}\text { Dialect } \\
\text { Similarity } \\
\text { (count) }\end{array}$ & $\begin{array}{c}2.209 * * * \\
(0.031)\end{array}$ & - & - & - & $\begin{array}{c}0.186 * * * \\
(0.025)\end{array}$ & $\begin{array}{c}0.118 * * \\
(0.046)\end{array}$ & $\begin{array}{c}0.204 * * * \\
(0.008)\end{array}$ & - \\
\hline $\begin{array}{l}\text { Dialect } \\
\text { Similarity } \\
\text { (Jaccard) }\end{array}$ & - & - & - & - & - & - & - & $\begin{array}{c}0.175^{* * * *} \\
(0.019)\end{array}$ \\
\hline $\begin{array}{l}\text { Geographical } \\
\text { Distance }\end{array}$ & - & $\begin{array}{c}-1.493 * * * \\
(0.012)\end{array}$ & - & $\begin{array}{c}-1.263 * * * \\
(0.036)\end{array}$ & $\begin{array}{c}-1.262 * * * \\
(0.035)\end{array}$ & $\begin{array}{c}-1.471 * * * \\
(0.028)\end{array}$ & $\begin{array}{c}-1.263 * * * \\
(0.013)\end{array}$ & $\begin{array}{c}-1.257 * * * \\
(0.035)\end{array}$ \\
\hline $\begin{array}{l}\text { Travel } \\
\text { Distance }\end{array}$ & - & - & $\begin{array}{c}-1.773 * * * \\
(0.014)\end{array}$ & $\begin{array}{c}-0.283 * * * \\
(0.029) \\
\end{array}$ & $\begin{array}{c}-0.200 * * * \\
(0.046)\end{array}$ & $\begin{array}{c}-0.460 * * * \\
(0.037)\end{array}$ & $\begin{array}{c}-0.224 * * * \\
(0.016) \\
\end{array}$ & $\begin{array}{c}-0.181 * * * \\
(0.045)\end{array}$ \\
\hline $\begin{array}{l}\text { Mills } \\
\text { Lambda }\end{array}$ & - & - & - & - & - & - & $\begin{array}{c}0.533 * * * \\
(0.018)\end{array}$ & - \\
\hline $\mathrm{R}^{2}$ & 0.558 & 0.744 & 0.731 & 0.744 & 0.745 & - & - & 0.745 \\
\hline Pseudo R² & - & - & - & - & - & 0.196 & - & - \\
\hline Cens. Obs. & - & - & - & - & - & - & 6,257 & - \\
\hline $\mathrm{N}$ & 186,025 & 186,025 & 186,025 & 186,025 & 186,025 & 192,282 & 192,282 & 186,025 \\
\hline
\end{tabular}

Notes: This table reports estimation results with fixed effects for both origin region r and target region s. In Columns (1)-(7) language similarity is measured by a count index, while Column (8) applies Jaccard's similarity index. Column (6) reports a Poisson regression of geographical distance and language similarity on the number of German migrants from region $r$ to $s$, $M_{r s}$. Column (7) reports the results from a Heckman selection model. In this specification, a first-stage selection considers the probability of a zero flow of migrants between region r and s. Zero flows drop out except in specifications (6) and (7). Geographical distance, travel time, and dialect similarity are in logs in all specifications. Robust standard errors are reported in parentheses.

*** statistically significant at the $1 \%$ level; ** statistically significant at the $5 \%$ level; * statistically significant at the $10 \%$ level. 
Table 4: Subsamples: Urban-Periphery

\begin{tabular}{|c|c|c|c|c|}
\hline & (1) & (3) & (3) & (4) \\
\hline & $\ln \left(M_{r s} / L_{r}\right)$ & $\ln \left(M_{r s} / L_{r}\right)$ & $\ln \left(M_{r s} / L_{r}\right)$ & $\ln \left(M_{r s} / L_{r}\right)$ \\
\hline & $U U$ & $P P$ & $U P$ & $P U$ \\
\hline Dialect Similarity & $\begin{array}{c}0.180 * * * \\
(0.040)\end{array}$ & $\begin{array}{l}0.065^{*} \\
(0.034)\end{array}$ & $\begin{array}{c}0.257 * * * \\
(0.040)\end{array}$ & $\begin{array}{c}0.208 * * * \\
(0.037)\end{array}$ \\
\hline Geographical Distance & $\begin{array}{c}-1.632 * * * \\
(0.059)\end{array}$ & $\begin{array}{c}-1.211 * * * \\
(0.054)\end{array}$ & $\begin{array}{c}-1.037 * * * \\
(0.061)\end{array}$ & $\begin{array}{c}-1.049 * * * \\
(0.060)\end{array}$ \\
\hline Travel Distance & $\begin{array}{c}0.340 * * * \\
(0.073)\end{array}$ & $\begin{array}{c}-0.486 * * * \\
(0.068)\end{array}$ & $\begin{array}{c}-0.351 * * * \\
(0.081)\end{array}$ & $\begin{array}{c}-0.362 * * * \\
(0.074)\end{array}$ \\
\hline $\mathrm{R}^{2}$ & 0.834 & 0.678 & 0.710 & 0.759 \\
\hline $\mathrm{N}$ & 31,174 & 64,308 & 45,176 & 45,367 \\
\hline
\end{tabular}

Notes: This table reports OLS results with fixed effects for both origin region r and target region s. In column (1) we consider migration flows where the origin and destination are both "ur ban" regions. In column (2) we consider migration flows where the origin and destination are both "peripheral" regions. In column (3) we consider urban-to-peripheral, and in column (4) we consider peripheral-to-urban migration flows. "Urban" regions are defined as regional types 1-5 in the classification system of the German Federal Board for Regional Planning (BBR). "Peripheral" areas are defined as regional types 6-9.Robust standard errors are reported in parentheses.

*** statistically significant at the $1 \%$ level; ** statistically significant at the 5\% level; * statistically significant at the $10 \%$ level. 
Table 5: Contemporaneous dialect similarity and migration - Instrumental variable regression

\begin{tabular}{|c|c|c|}
\hline & $\begin{array}{c}(1) \\
\ln \left(M_{r s} / L_{r}\right)\end{array}$ & $\begin{array}{c}(2) \\
\ln \left(M_{r s} / L_{r}\right)\end{array}$ \\
\hline & $O L S$ & $I V$ \\
\hline Contemporaneous Dialect Similarity & $\begin{array}{l}0.098 * * * \\
(0.016)\end{array}$ & $\begin{array}{l}0.184 * * * \\
(0.011)\end{array}$ \\
\hline Geographical Distance & $\begin{array}{l}-1.654 * * * \\
(0.087)\end{array}$ & $\begin{array}{l}-1.525 * * * \\
(0.052)\end{array}$ \\
\hline Travel Distance & $\begin{array}{l}-0.115 \\
(0.105)\end{array}$ & $\begin{array}{c}-0.071 \\
(0.065)\end{array}$ \\
\hline Historical Dialect Similarity & -- & $\begin{array}{l}0.674 * * * \\
(0.009)\end{array}$ \\
\hline F-Test of Excluded Instrument & -- & $6,291.7$ \\
\hline (Second Stage) $\mathrm{R}^{2}$ & 0.877 & 0.874 \\
\hline $\mathrm{N}$ & 4,549 & 4,549 \\
\hline
\end{tabular}

Notes: This table reports OLS and IV results for the effect of contemporaneous dialect similarity on gross migration flows between 69 Bavarian regions.

Regressions include fixed effects for both origin region $r$ and target region s. In Column (2), historical dialect similarity is used as instrument for contemporaneous dialect similarity. Robust standard errors are reported in parentheses.

*** statistically significant at the 1\% level; ** statistically significant at the 5\% level; * statistically significant at the $10 \%$ level. 
Table 6: Region-Pair-Specific Differences

(1)

(2)

(3)

(4)

(5)

\begin{tabular}{|c|c|c|c|c|c|}
\hline & $\ln \left(M_{r s} / L_{r}\right)$ & $\ln \left(M_{r s} / L_{r}\right)$ & $\ln \left(M_{r s} / L_{r}\right)$ & $\ln \left(M_{r s} / L_{r}\right)$ & $\ln \left(M_{r s} / L_{r}\right)$ \\
\hline Dialect Similarity & $\begin{array}{c}0.184 * * * \\
(0.025)\end{array}$ & $\begin{array}{c}0.170 * * * \\
(0.025)\end{array}$ & $\begin{array}{c}0.132 * * * \\
(0.025)\end{array}$ & $\begin{array}{c}0.186^{* * * *} \\
(0.025)\end{array}$ & $\begin{array}{c}0.114 * * * \\
(0.025)\end{array}$ \\
\hline Geographical Distance & $\begin{array}{c}-1.265^{* * *} \\
(0.035)\end{array}$ & $\begin{array}{c}-1.254 * * * \\
(0.035)\end{array}$ & $\begin{array}{c}-1.245^{* * *} \\
(0.035)\end{array}$ & $\begin{array}{c}-1.262^{* * *} \\
(0.035)\end{array}$ & $\begin{array}{c}-1.243 * * * \\
(0.035)\end{array}$ \\
\hline Travel Distance & $\begin{array}{c}-0.201 * * * \\
(0.046)\end{array}$ & $\begin{array}{c}-0.193 * * * \\
(0.046)\end{array}$ & $\begin{array}{c}-0.161 * * * \\
(0.045)\end{array}$ & $\begin{array}{c}-0.200^{* * *} * \\
(0.046)\end{array}$ & $\begin{array}{c}-0.157 * * * \\
(0.045)\end{array}$ \\
\hline Religious Borders & $\begin{array}{c}0.018 \\
(0.011)\end{array}$ & - & - & - & $\begin{array}{c}0.026 * * \\
(0.010)\end{array}$ \\
\hline $\begin{array}{l}\text { Historical Differences in } \\
\text { Industrial Structures }\end{array}$ & - & $\begin{array}{c}-1.002 * * * \\
(0.066)\end{array}$ & - & - & $\begin{array}{c}-0.934 * * * \\
(0.065)\end{array}$ \\
\hline Historical Political Borders & - & - & $\begin{array}{c}-0.300 * * * \\
(0.018)\end{array}$ & - & $\begin{array}{c}-0.295 * * * \\
(0.018)\end{array}$ \\
\hline Historical Travel Distance & - & - & - & $\begin{array}{c}0.001 \\
(0.002)\end{array}$ & $\begin{array}{c}0.003 \\
(0.002)\end{array}$ \\
\hline $\mathrm{R}^{2}$ & 0.745 & 0.746 & 0.749 & 0.745 & 0.751 \\
\hline $\mathrm{N}$ & 186,025 & 186,025 & 186,025 & 186,025 & 186,025 \\
\hline
\end{tabular}

Notes: This table reports OLS results with fixed effects for both origin region $r$ and target region s. In column (1) we control for differences in religious denominations in 1890 by including a dummy variable that equals unity if the majority of the population in the source region had a different religion than those in the destination region. In column (2) we include a measure for

industry differences in 1907 meassured as sum of differences in the employment shares of 24 industries. In column (3) we include a dummy that equals unity if the current migration flow extends across a historical administrative border between 38 member states and 4 independent cities that were part of the German Confederation at the time of its foundation in 1815. In column (4) we control for historic travel distance measured on a scale from 0 (no distance) to 7 (highest distance). In column (5), we finally include all controls at the same time.

Robust standard errors are reported in parentheses. *** statistically significant at the 1\% level; ** statistically significant at the 5\% level; * statistically significant at the $10 \%$ level. 
Table 7: Subsample: East-West

\begin{tabular}{|c|c|c|c|}
\hline & (1) & (2) & (3) \\
\hline & $\ln \left(M_{r s} / L_{r}\right)$ & $\ln \left(M_{r s} / L_{r}\right)$ & $\ln \left(M_{r s} / L_{r}\right)$ \\
\hline & East-West & West-East & East-West and West-East \\
\hline Dialect Similarity & $\begin{array}{c}0.213 * * * \\
(0.036)\end{array}$ & $\begin{array}{c}0.160 * * * \\
(0.033)\end{array}$ & $\begin{array}{c}0.187 * * * \\
(0.024)\end{array}$ \\
\hline Geographical Distance & $\begin{array}{c}-1.580 * * * \\
(0.067)\end{array}$ & $\begin{array}{c}-1.443^{* * *} \\
(0.073)\end{array}$ & $\begin{array}{c}-1.513 * * * \\
(0.050)\end{array}$ \\
\hline Travel Distance & $\begin{array}{c}-0.507 * * * \\
(0.082)\end{array}$ & $\begin{array}{c}-0.508 * * * \\
(0.073)\end{array}$ & $\begin{array}{c}-0.507 * * * \\
(0.056)\end{array}$ \\
\hline $\mathrm{R}^{2}$ & 0.708 & 0.534 & 0.633 \\
\hline $\mathrm{N}$ & 35,581 & 34,023 & 69,604 \\
\hline
\end{tabular}

Notes: This table reports OLS results with fixed effects for both origin region r and target region s. In column (1) we consider migration flows where the origin is located in former East Germany and the destination is located in former West Germany. In column (2) we consider migration flows where the origin is located in former West Germany and the destination is located in

former East Germany. In column (3) we pool East-to-West and West-to-East migration flows. Robust standard errors are reported in parentheses.

*** statistically significant at the $1 \%$ level; ** statistically significant at the $5 \%$ level; * statistically significant at the $10 \%$ level. 
Table 8a: Subsample: Soil Quality

\begin{tabular}{|c|c|c|c|c|}
\hline & (1) & (2) & (3) & (4) \\
\hline & $\begin{array}{c}\ln \left(M_{r s} / L_{r}\right) \\
\text { Good-Good }\end{array}$ & $\begin{array}{c}\ln \left(M_{r s} / L_{r}\right) \\
\text { Bad-Bad }\end{array}$ & $\begin{array}{c}\ln \left(M_{r s} / L_{r}\right) \\
\text { Good-Bad }\end{array}$ & $\begin{array}{c}\ln \left(M_{r s} / L_{r}\right) \\
\text { Bad-Good }\end{array}$ \\
\hline Dialect Similarity & $\begin{array}{c}0.179 * * * \\
(0.032)\end{array}$ & $\begin{array}{l}0.099 * \\
(0.056)\end{array}$ & $\begin{array}{c}0.223 * * * \\
(0.028)\end{array}$ & $\begin{array}{c}0.194 * * * \\
(0.052)\end{array}$ \\
\hline Geographical Distance & $\begin{array}{c}-1.431 * * * \\
(0.048)\end{array}$ & $\begin{array}{c}-1.127 * * * \\
(0.071)\end{array}$ & $\begin{array}{c}-1.123 * * * \\
(0.056)\end{array}$ & $\begin{array}{c}-1.195 * * * \\
(0.070)\end{array}$ \\
\hline Travel Distance & $\begin{array}{c}0.004 \\
(0.063)\end{array}$ & $\begin{array}{c}-0.510 * * * \\
(0.090)\end{array}$ & $\begin{array}{c}-0.333 * * * \\
(0.068)\end{array}$ & $\begin{array}{c}-0.259 * * * \\
(0.091)\end{array}$ \\
\hline $\mathrm{R}^{2}$ & 0.748 & 0.760 & 0.751 & 0.727 \\
\hline $\mathrm{N}$ & 71,836 & 26,529 & 43,803 & 43,857 \\
\hline
\end{tabular}

Notes: This table reports OLS results with fixed effects for both origin region r and target region s. In column (1) we consider migration flows where the origin and destination both have good soil quality. In column (2) we consider migration flows where the origin and destination both have bad soil quality. In column (3) we consider migration flows from regions with good to regions with bad soil quality, and in column (4) we consider migration flows from regions with bad to regions with good soil quality. "Good soil quality" refers to regions with no limitations to agricultural use according to the European Soil Database (esdb) compiled by the European Soil Data Centre. "Bad soil quality" refers to regions with one ore more limitations to agricultural use. Robust standard errors are reported in parentheses.

*** statistically significant at the $1 \%$ level; ** statistically significant at the $5 \%$ level; * statistically significant at the $10 \%$ level. 
Table 8b: Subsample: Slope

(1)

\begin{tabular}{|c|c|c|c|c|}
\hline & $\begin{array}{c}\ln \left(M_{r s} / L_{r}\right) \\
\text { Steep-Steep }\end{array}$ & $\begin{array}{c}\ln \left(M_{r s} / L_{r}\right) \\
\text { Flat-Flat }\end{array}$ & $\begin{array}{c}\ln \left(M_{r s} / L_{r}\right) \\
\text { Steep-Flat }\end{array}$ & $\begin{array}{c}\ln \left(M_{r s} / L_{r}\right) \\
\text { Flat-Steep }\end{array}$ \\
\hline Dialect Similarity & $\begin{array}{c}0.056 \\
(0.036)\end{array}$ & $\begin{array}{c}0.246^{* * * *} \\
(0.050)\end{array}$ & $\begin{array}{c}0.298 * * * \\
(0.041)\end{array}$ & $\begin{array}{c}0.304 * * * \\
(0.044)\end{array}$ \\
\hline Geographical Distance & $\begin{array}{c}-1.359 * * * \\
(0.042)\end{array}$ & $\begin{array}{c}-1.335 * * * \\
(0.073)\end{array}$ & $\begin{array}{c}-1.110^{* * * *} \\
(0.083)\end{array}$ & $\begin{array}{c}-1.094 * * * \\
(0.072)\end{array}$ \\
\hline Travel Distance & $\begin{array}{c}-0.281 * * * \\
(0.057)\end{array}$ & $\begin{array}{c}-0.286 * * * \\
(0.096)\end{array}$ & $\begin{array}{c}-0.284 * * * \\
(0.101)\end{array}$ & $\begin{array}{c}-0.266 * * * \\
(0.087)\end{array}$ \\
\hline $\mathrm{R}^{2}$ & 0.734 & 0.832 & 0.750 & 0.717 \\
\hline $\mathrm{N}$ & 88,628 & 18,236 & 39,250 & 39,911 \\
\hline
\end{tabular}

Notes: This table reports OLS results with fixed effects for both origin region r and target region s. In column (1) we consider migration flows where the origin and destination both are steep regions. In column (2) we consider migration flows where the origin and destination both are flat regions. In column (3) we consider migration flows from regions with steep slope to regions with good slope, and in column (4) we consider migration flows from regions with flat slope to regions with good slope. For each region, slope is measured as the difference between the maximum and minimum elevation in meters. We can then classify a region ith above-average slope as "steep", and with below-average slope as "flat". Robust standard errors are reported in parentheses.

*** statistically significant at the 1\% level; ** statistically significant at the 5\% level; * statistically significant at the $10 \%$ level. 
Figure 1a: Exemplary Questionnaire of the Language Survey
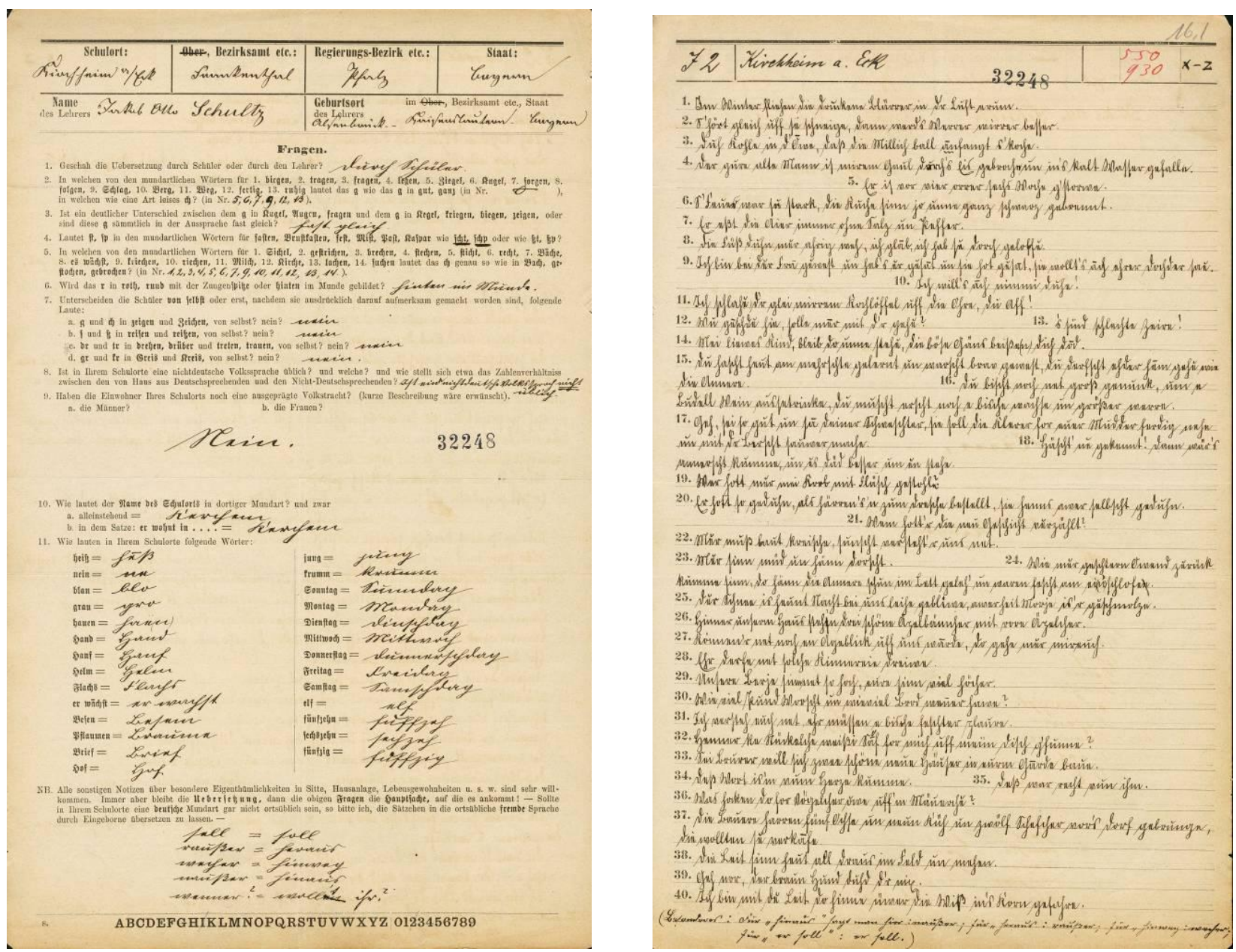
Figure 1b: Exemplary Hand-Drawn Map by Georg Wenker

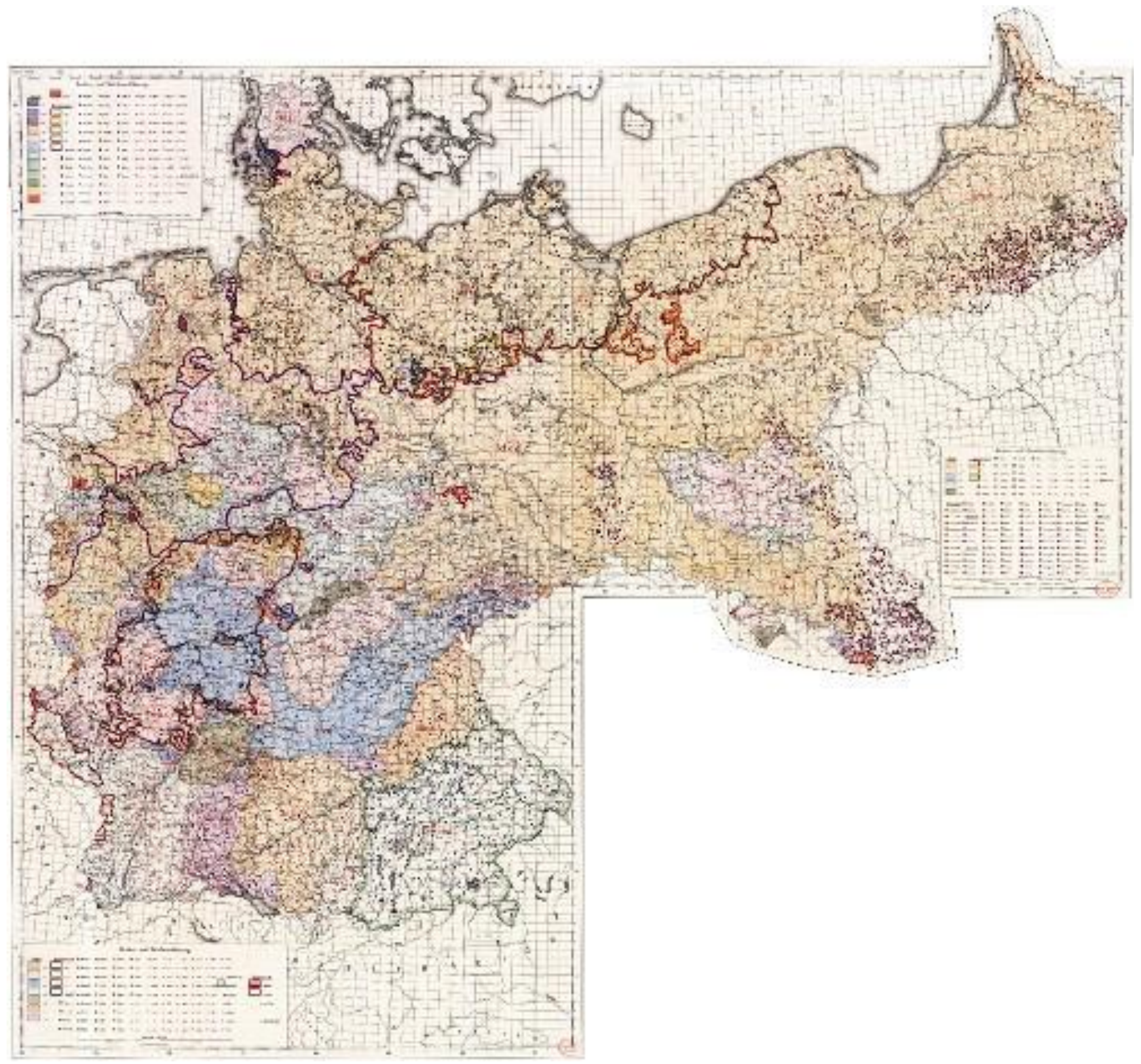


Figure 2: Distribution of Religious Denomination in Southern Germany

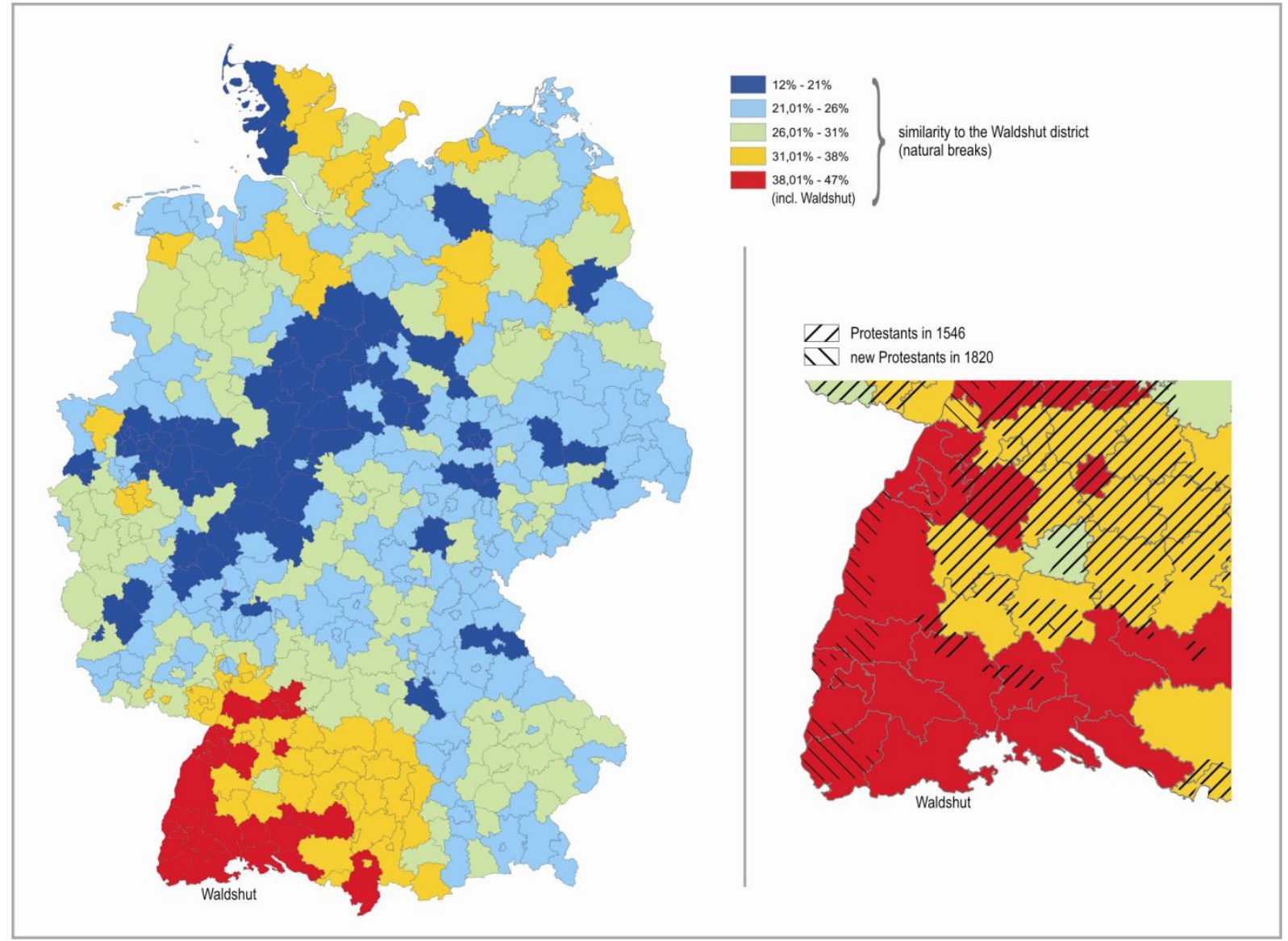

Notes: Similarity of all districts to the reference point Waldshut (marked). Red indicates highest familiarity and yellow indicates higher familiarity, while the green and blue indicate less familiarity. Data on religious denomination are taken from Steger et al. (1989). 


\section{Figure 3: The Language Enclave Goslar}

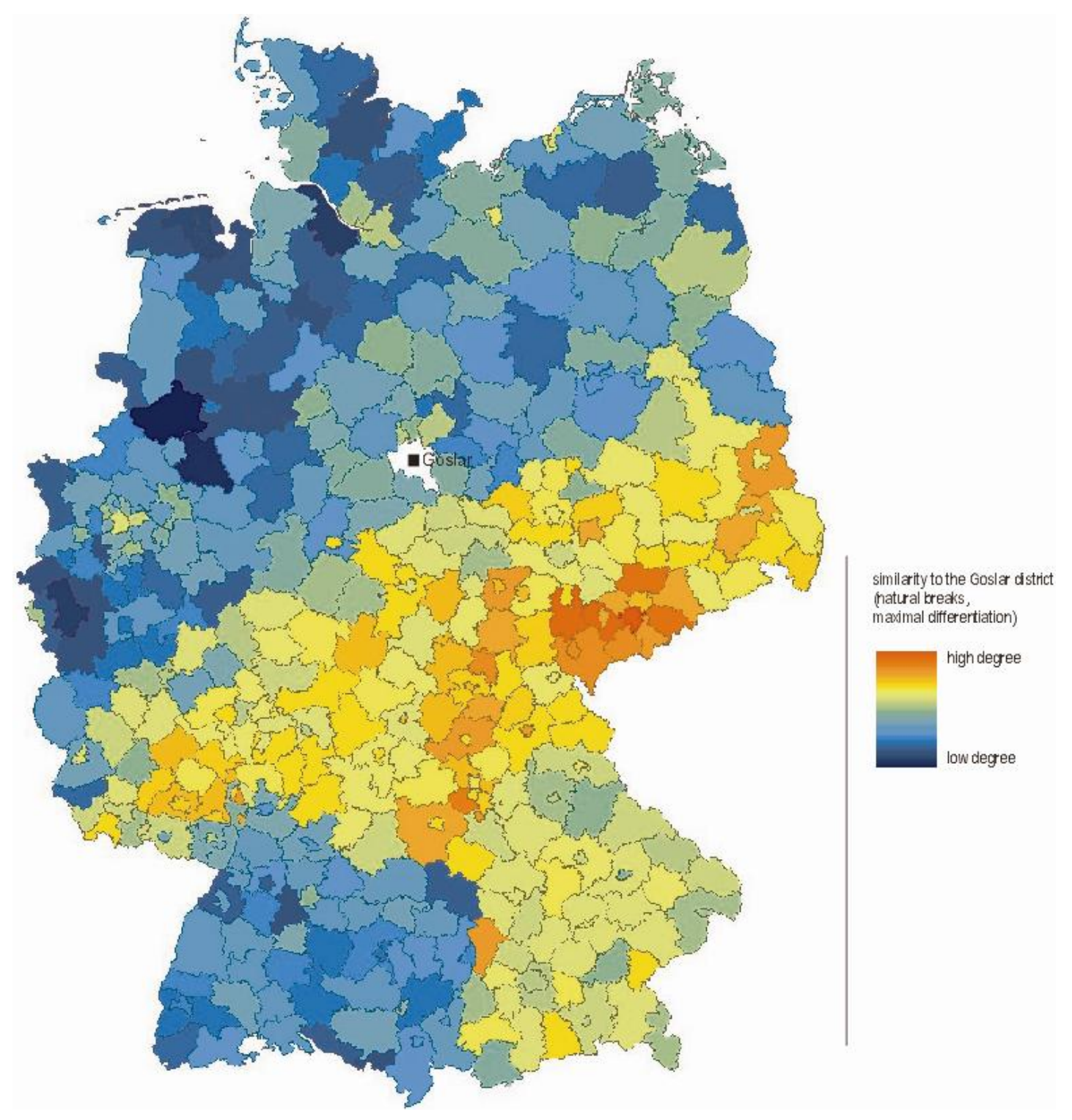

Notes: Similarity of all districts to the reference point Goslar (white spot). Red indicates highest familiarity and warmer tints (yellow and green) indicate higher familiarity, while the bluish tints indicate less familiarity. 
Figure 4: Dialect similiarity with Passau $-19^{\text {th }}$ century and today

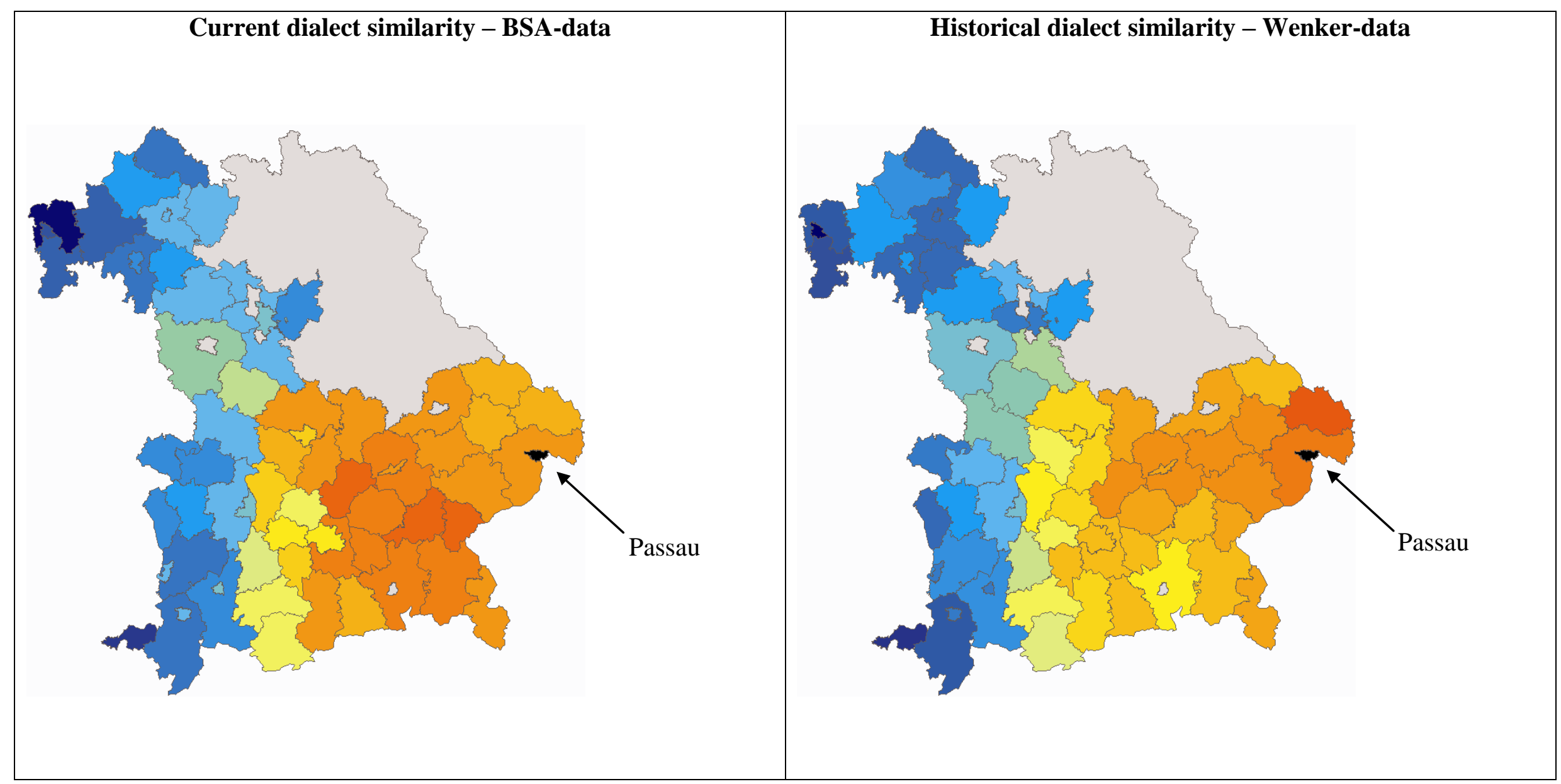

Notes: Similarity of all districts to the reference point Passau (black spot). Red indicates highest familiarity and warmer tints (yellow and green) indicate higher familiarity, while the bluish tints indicate less familiarity. 


\section{Table A1: Extended Data Description}

\begin{tabular}{|c|c|}
\hline Variable & Description and Source \\
\hline Geographical Distance & $\begin{array}{l}\text { The geographical distance between two districts is calculated as Euclidean distance in kilometers between each pair of dis- } \\
\text { tricts' centroids. }\end{array}$ \\
\hline Historical Political Borders & $\begin{array}{l}\text { Historical borders refer to } 38 \text { member states and } 4 \text { independent cities that were part of the German Confederation at its } \\
\text { foundation in 1815. Data are taken from a map in Putzger - Historischer Weltatlas, } 89^{\text {th }} \text { edition, 1965. The dummy equals } \\
\text { unity if a region pair does not belong to the same historic state, and zero otherwise. }\end{array}$ \\
\hline Historical differences in industrial structure & 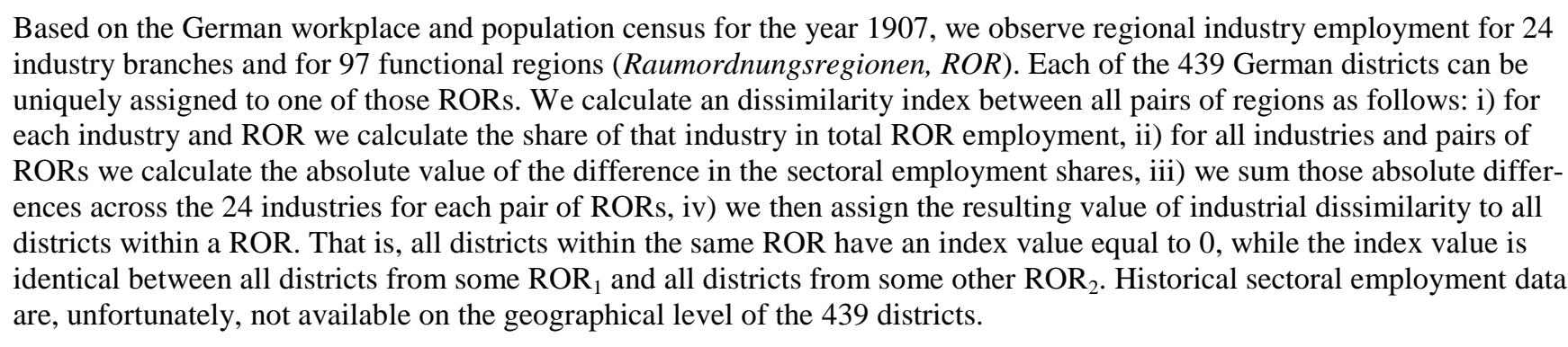 \\
\hline Historical travel distance & $\begin{array}{l}\text { The measure is based on the route plan for a comprehensive German railway system outline by Friedrich List in } 1833 \text {. } \\
\text { Based on List's plans for a railway system, we define } 12 \text { major hubs (knots) and } 22 \text { spokes (railway lines) between or from } \\
\text { these knots. We then surround this route system with a } 50 \mathrm{~km} \text { corridor and determine each district as either being connected } \\
\text { or not connected to the railway system, and we further determine which of the } 22 \text { railway line(s) intersect or border the } \\
\text { district. Based on this categorization, we measure the historical travel distance as the number of knots between any pair of } \\
\text { districts. District pairs in which at least one district is not intersecting or bordering any railway line are coded with the } \\
\text { highest possible distance value of } 7 \text {; all other district pairs have a distance value between } 0 \text { (at the same line) and } 6 \text {. } \\
\text { For district pairs in which at least one district is not intersecting or bordering more than one railway line, we choose the } \\
\text { minimum distance. }\end{array}$ \\
\hline
\end{tabular}




\section{Variable}

\section{Religious border dummy (1890)}

Soil

Slope

Travel Distance (contemporaneous)

\section{Urban}

\section{Description and Source (continued)}

The districts' historic shares of Catholics and Protestants in 1890 are calculated from a map in Meyers Konversations Lex$i k o n, 4^{\text {th }}$ edition, 1885-1892. The dummy equals unity if a region pair has different religious affiliations, i.e. an above average share of Catholics and Protestants respectively.

Soil concerns the main limitation to agricultural exploitation. The variable distinguishes between regions that have no limitation to agriculture and regions that have limitations due to less suitable soil characteristics.

1 no limitation to agricultural use

2 gravelly (over $35 \%$ gravels diameter $<7.5 \mathrm{~cm}$ )

3 stony (presence of stones diameter $>7.5 \mathrm{~cm}$, impracticable mechanization)

4 lithic (coherent and hard rock within $50 \mathrm{~cm}$ )

5 concretionary (over $35 \%$ concretions diameter $<7.5 \mathrm{~cm}$ near the surface)

6 saline (electric conductivity $>4 \mathrm{mS} . \mathrm{cm}-1$ within $100 \mathrm{~cm}$ )

7 others

For our purpose, we collapse all limitations and create a binary variable that distinguishes regions that are more or less

suitable for agriculture. The data stem from the European Soil Database (esdb) and are compiled by the European Soil Data Centre.

Slope is measured as the difference between the maximum and minimum elevations in meters. Flat regions are regions with a below average slope while steep regions are characterized by an above average slope.

The travel distance is calculated in car minutes from one district's capital to the other.

This variable is based on a standard classification of German districts (siedlungsstrukturelle Kreistypen) according to their density and their spatial status (cf. Federal Office for Building and Regional Planning 2003). For our purpose, urban areas are districts characterized by a minimum city size of 100,000 inhabitants or a population density larger than 150 inhabitants per $\mathrm{km}^{2}$. All other regions are classified as peripheral areas. 
